ISSN: 0213-2079 - ISSN electrónico: 2386-3889

DOI: https://doi.org/10.14201/shhmo2020422255288

\title{
LOS PEREIRA, CARDOSO Y LADRÓN DE GUEVARA: TRES FAMILIAS ESPECIALIZADAS EN EL ABASTECIMIENTO DE PERTRECHOS Y BASTIMENTOS NAVALES EN EL REINADO DE FELIPE IV
}

The Pereira, Cardoso and Ladrón de Guevara: Three Families Specialized in the Supply of Naval Equipment in the Philip IV Kingdom

\author{
Javier GÓMEZ MESAS \\ Universitat Pompeu Fabra \\ javier.gomezm@upf.edu
}

Fecha de recepción: 28/01/2020

Fecha de aceptación: 18/09/2020

RESUMEN: Tras la consolidación de la casa de negocios de los Pereira en Castilla durante la década de 1620, la casa de negocios de los Cardoso heredó sus negocios y se especializó en la provisión de bastimentos y pertrechos a las flotas y escuadras de la monarquía hispánica. A pesar de las restricciones mercantiles con las Provincias Unidas tras la reanudación de hostilidades en 1621, y posteriormente con Francia en 1635, la compañía que formaron con los Ladrón de Guevara garantizó el acopio de los enseres necesarios para sostener el poderío naval de los Austrias durante las décadas sucesivas de 1630 y 1640.

Gracias a la operatividad de sus redes mercantiles, integradas por múltiples agentes y corresponsales diseminados en puntos estratégicos, y las conexiones con el capital sefardita, los Cardoso-Ladrón de Guevara desempeñaron una estrategia inversora diversificada a gran escala cuyo

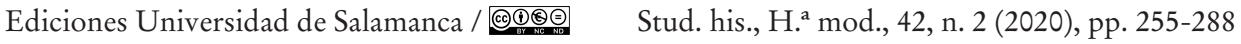


JAVIER GÓMEZ MESAS

LOS PEREIRA, CARDOSO Y LADRÓN DE GUEVARA: TRES FAMILIAS ESPECIALIZADAS

EN EL ABASTECIMIENTO DE PERTRECHOS Y BASTIMENTOS NAVALES EN EL REINADO DE FELIPE IV

negocio vehicular fue el abasto de pertrechos y bastimentos a las unidades navales de la Corona.

Palabras clave: armadas; aprovisionamiento naval; asentistas judeoconversos.

ABSTRACT: After the consolidation of the Pereira business house in Castile during the 1620s, the Ladrón de Guevara y Cardoso mercantile company inherited its businesses and became specialized in the provision of naval supplies to the Hispanic monarchy fleets. Despite trade restrictions with the United Provinces after the resumption of hostilities in 1621, and later with France in 1635, the company guaranteed the stockpiling necessary to sustain the naval power of the Habsburgs across the 1630-1640s.

On account of their commercial networks, built into multiple agents and correspondents scattered in strategic points, and the connections with Sephardic capital, the Cardoso-Ladrón de Guevara carried out a diversified and large-scale investment strategy. The success of those multiple investments settled out ensure the development of the company's central business: the supply of the different naval units of the Hispanic monarchy

Keywords: army; naval supplies; Sephardic capital.

El presente artículo indaga en la trayectoria de tres familias -Ladrón de Guevara, Cardoso y Pereira- vinculadas entre sí por negocios en común y enlaces matrimoniales que les permitían acometer una estrategia inversora múltiple en la que participaban tanto judeoconversos como cristianos viejos. A lo largo de las décadas de 1620, 1630 y 1640 , hombres de negocios de estas familias concurrieron de forma recurrente en las finanzas del reino, bien como asentistas por cuenta propia o asociados con sus clientelas, y se especializaron en las provisiones de pertrechos y bastimentos navales. Gracias a la disposición de una tupida red de agentes y corresponsales en distintos puntos estratégicos, las casas de negocios acometieron una actividad comercial a gran escala, intercambiando mercancías de dispar procedencia y gestionando el trasvase de capitales desde la península hacia los centros de acopio de enseres navales y las plazas de crédito europeas.

Los Pereira provenían del Aveiro portugués aunque desde 1618 residían en Casti1la. Durante la década de 1620, los hermanos Simón y Lorenzo Pereira consolidaron sus negocios primigenios y diversificaron sus inversiones, empeñando el rédito de los tratos comerciales en actividades financieras. Los continuos servicios ofrecidos a la Corona en una época de necesidad crediticia se tradujeron en la obtención de

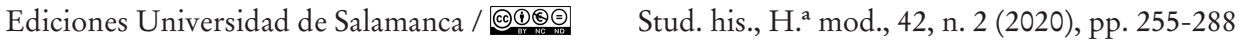


JAVIER GÓMEZ MESAS

LOS PEREIRA, CARDOSO Y LADRÓN DE GUEVARA: TRES FAMILIAS ESPECIALIZADAS

EN EL ABASTECIMIENTO DE PERTRECHOS Y BASTIMENTOS NAVALES EN EL REINADO DE FELIPE IV

prebendas, que consolidaron su posición en el seno de la comunidad judeoconversa portuguesa residente en Castilla y alejaron las pesquisas del Santo Oficio. Alternando con su labor de tesoreros de la hermandad de San Antonio de los Portugueses, los Pereira, concurrieron en el gran asiento ofrecido por el capital luso tras la suspensión de pagos de 1627, irrumpiendo desde dicho año en las finanzas generales del reino (Pulido Serrano, 2014: 43-50; Domínguez Ortiz, 1960: 127-132). No obstante, solo cuatro años más tarde, ambos hermanos fallecieron, y fue entonces cuando Alfonso Cardoso, su cuñado, se hizo con la dirección de la casa (Boyajian, 1983: 35-37).

Los Cardoso eran naturales de Lisboa donde la familia gestionaba el tráfico de diamantes y de esclavos a través de la ruta Goa-Lisboa. Tras la muerte de los Pereira, Alfonso y Diego Cardoso, continuaron con sus propios negocios y los legados por los del Aveiro, haciendo de la provisión de pertrechos y bastimentos a las distintas unidades navales, el negocio estrella de su casa de negocios (Álvarez Nogal, 1997: 106-08). Gradualmente, la planificación inversora de los Cardoso fue diversificándose, aminorando el riesgo individual de cada una de las operaciones llevadas a cabo, y adquirió una mayor dimensión, requiriendo una mayor cantidad de agentes y un eficiente sistema de pagos.

A pesar de las restricciones comerciales impuestas por la Corona tras la reanudación de las hostilidades con las Provincias Unidas en 1621, las adehalas y facultades negociadas por ambos hermanos en los asientos de provisiones, ofrecieron cierta cobertura legal a sus actividades mercantiles a gran escala. Ello se debió a un hecho fundamental: las vituallas que ofrecían a la Corona eran imprescindibles para equipar el dispositivo naval. A su vez, la administración de rentas estratégicas como las salinas, ofrecía un acceso directo a un bien altamente demandado en el mar del Norte (Ayán, 1992: 917-919; Herrero Sánchez, 1993: 173-177)¹. Mediante la exportación de sal, los Cardoso obtenían los pertrechos y el grano provenientes del mar Báltico, comercializados en su mayor parte a través de Ámsterdam, que habían sido convenidos previamente en los asientos de provisiones².

Del mismo modo, el cobro de sus consignaciones a largo plazo en efectos «relativamente» seguros como la plata americana permitió el desarrollo de otras inversiones consustanciales al negocio estrella que ofrecieron una gran rentabilidad. Asociados con los Pallavicino, los Cardoso remitieron los metales americanos a Italia a través de la escuadra de galeras de España. Así, la plata viajaba desde Sevilla a Génova, donde los Pallavicino gestionaban su depósito y distribución a las ferias de cambio italianas (Álvarez Nogal, 1997: 106, 107).

1. Remitimos a la bibliografía citada para conocer la importancia de la sal en el eje atlántico.

2. Para conocer la procedencia de cada uno de los pertrechos navales, remitimos a Serrano Mangas, 1983: 21-26.

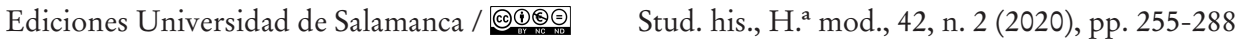


JAVIER GÓMEZ MESAS

LOS PEREIRA, CARDOSO Y LADRÓN DE GUEVARA: TRES FAMILIAS ESPECIALIZADAS

EN EL ABASTECIMIENTO DE PERTRECHOS Y BASTIMENTOS NAVALES EN EL REINADO DE FELIPE IV

El control de los canales de distribución de enseres navales permitió a la casa de negocios, concurrir de forma simultánea en los asientos de provisiones y factorías de las distintas unidades navales. Alfonso y Diego Cardoso se convirtieron en abastecedores recurrentes de la Armada del Mar Océano durante la década de 1630; mientras, Alfonso Cardoso fue factor de la escuadra de galeras de España por cinco años (1637-1642), aunque tras su fallecimiento en 1639, la titularidad de la factoría recayó en su yerno Fernando Ladrón de Guevara ${ }^{3}$. Con el fin de monopolizar la distribución de enseres navales, los Cardoso se asociaron con los Ladrón de Guevara en una compañía que quedó ratificada con el matrimonio entre Diego Cardoso y una de las hijas de Martín Ladrón de Guevara.

Los Ladrón de Guevara provenían de Estella, una población en la zona occidental del reino de Navarra ${ }^{4}$. Hasta 1646, el jefe de la casa de negocios familiar fue Martín Ladrón de Guevara y tras su muerte, su hijo Fernando Ladrón de Guevara se encargó de los asuntos de la casa. Según Serrano Mangas (1990: 73-114) durante cerca de dos décadas, Martín Ladrón de Guevara se convirtió en el principal encargado del apresto, carena y abasto de las unidades navales de la Carrera de Indias, dejando un gran vacío a su muerte. También asistió de forma puntual a las galeras o la armada del Mar Océano con sus propios bajeles y los útiles navales requeridos. Gracias a los vínculos con el capital sefardita y los enlaces del eje atlántico que les proporcionó la alianza con los Cardoso, la actividad de los Ladrón de Guevara fue constante. Asimismo, en virtud de los distintos asientos concertados, administraron rentas que gravaban productos de consumo básico que podían ser empleados como bastimentos de las flotas.

A la muerte de Alfonso Cardoso en 1639, Fernando Ladón de Guevara administró la casa de negocios de los Cardoso, en tanto que su padre Martín Ladrón de Guevara dirigía los asuntos generales de la compañía. Una vez Martín Ladrón de Guevara falleció, ambas casas recayeron en una única dirección bajo Fernando Ladrón de Guevara que continuó con la estrategia inversora legada por sus predecesores. No obstante, el navarro no se mantuvo en la dirección de una compañía que terminó disolviendo al ocupar una plaza en la Contaduría Mayor de Cuentas y gestionar de forma autónoma los asuntos de la casa de negocios familiar. En cuanto a la casa de los Cardoso, una nueva generación de hombres de negocios formados desde su

3. Seis años después de heredar la casa de los Cardoso, Fernando Ladrón de Guevara reclamaba la condonación de las deudas que la Real Hacienda tenía pendientes con el factor Alfonso Cardoso hasta su muerte en 1639. Cuentas de Fernando Ladrón de Guevara como administrador de la casa de Alfonso Cardoso. 21/08/1645. Madrid. AHN, Hacienda, lib.7890, fol.190

4. Genealogía de Fernando Ladrón de Guevara. 09/09/1643. Madrid. AHN, OM, Expedientillos_Santiago, exp. 2526.

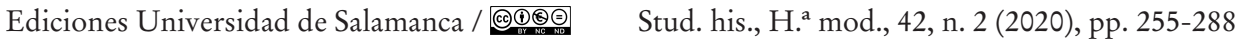


juventud en el seno de la compañía tomaron el relevo: Ventura Donis (Sanz Ayán, 1998: 33-57) y Duarte de Acosta (Gómez Mesas, 2020: 342-345).

Los hombres de negocios de estas tres casas conformaron a lo largo del tiempo una estructura empresarial dinámica y variada, que abarcaba múltiples espacios y operaciones de diversa índole, lo que posibilitó el concierto repetido de asientos de provisiones. En líneas generales, los términos expresados en los contratos reflejaban que, al menos en un principio, los hombres de negocios percibirían por sus provisiones un tipo de interés cercano al $8 \%$, junto a un $1 \%$ adicional por cada mes de demora en el retraso de las consignaciones (Sanz Ayán, 1989: 70-72). En la negociación de los asientos, los hombres de negocios obtuvieron amplios beneficios sociales y de prestigio -incluidos mayormente como adehalas de incuantificable valor-. Estas adehalas denotaban la posición social adquirida gracias al mundo de los negocios y entre ellas podemos destacar: oficios (Andújar Castillo, 2018: 169-176), mercedes de hábito (Giménez Carrillo, 2015: 673-683) o rentas estratégicas. Para garantizar el tránsito de mercancías y capitales en el seno de la red mercantil, los asentistas acordaron con la Corona ventajosas conducciones que cubrían la mayor parte de los gajes de transporte de divisas y materiales, reduciendo el riesgo de la Corona que no gestionaba de forma directa la logística mercantil (Álvarez Nogal, 2005: 400-405). Por último, los hombres de negocios contaban con facultades que incluían licencias de saca o licencias especiales con las que poder eludir las restricciones comerciales, exportar/importar determinados bienes y transportar moneda fuera de la península (Sanz Ayán, 2013: 138-142; Rodríguez Grajera, 2015: 961-973). 
JAVIER GÓMEZ MESAS

LOS PEREIRA, CARDOSO Y LADRÓN DE GUEVARA: TRES FAMILIAS ESPECIALIZADAS EN EL ABASTECIMIENTO DE PERTRECHOS Y BASTIMENTOS NAVALES EN EL REINADO DE FELIPE IV

Tabla 1. Vinculación entre las familias Pereira, Cardoso y Ladrón de Guevara.
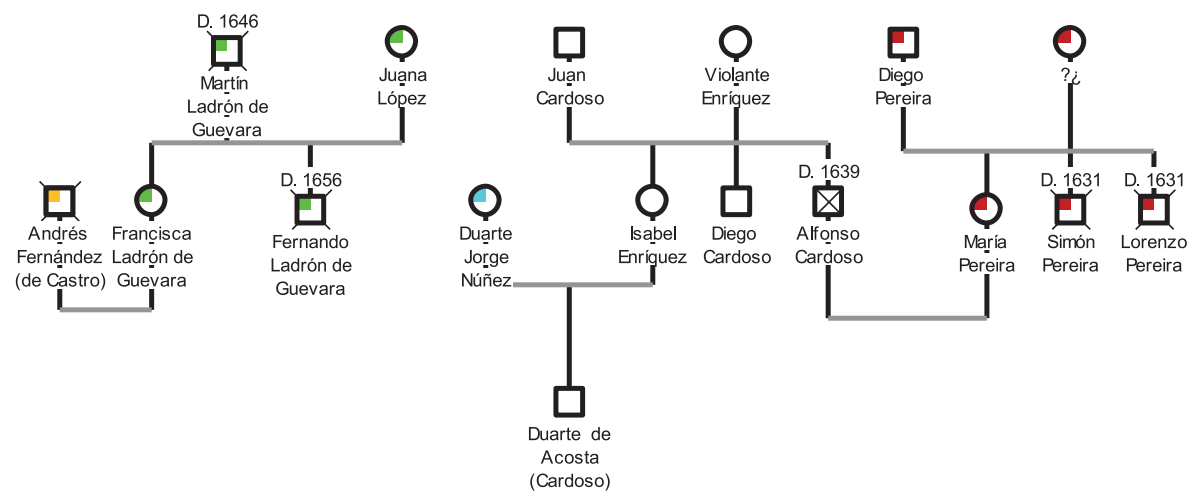

Fuente ${ }^{5}$.

\section{LA INSTALACIÓN DE LOS PEREIRA EN CASTILLA Y LA SUCESIÓN DE LA CASA DE NEGOCIOS EN MANOS DE LOS CARDOSO}

La familia Pereira, natural del Aveiro, se desplazó a Sevilla en 1618, bajo la dirección de jefe de la casa de negocios, Diego Pereira, junto a sus hijos Simón y Lorenzo Pereira, que después se convirtieron en dos importantes asentistas (Boyajian, 1983: 35-37). Tras la anexión de Portugal a los dominios hispánicos, la ciudad hispalense se convirtió en el principal foco de destino de las poblaciones emigradas de Portugal debido a la proximidad geográfica entre ambas regiones, al temor a la

5. Esta genealogía solo muestra los vínculos establecidos entre las tres familias. Para los Cardoso. Carta de Francisco Gómez Silveira a don Antonio de Benavides al Consejo de Órdenes contra la concesión del hábito militar a Duarte de Acosta. 02/07/1655. Madrid. AHN, OM_Caltarava_Reprobados, Exp. 17; para conocer la vinculación familiar entre los Ladrón de Guevara y los Cardoso. Consulta de la Junta de Armadas en la que se ofrece una merced de hábito militar como adehala de un asiento suscrito por Martín Ladrón de Guevara y Diego Cardoso. 30/01/1643. Madrid. AHN, Santiago_Expedientillos, Exp. 2609; la familia Ladrón de Guevara tras la muerte de Martín Ladrón de Guevara. Testamento de Fernando Ladrón de Guevara. 02/06 /1656. Madrid. AHPNM, leg. 7844, fol. 704 r-717 r; los vínculos matrimoniales entre los Cardoso y los Pereira. Por Fernando Ladrón de Guevara, administrador de la casa y negocios de Alfonso Cardoso, con María Pereira, mujer de Gerónimo de Fonseca, como tutora y curadora de sus hijos y de Alfonso Cardoso su primer marido contra Doña Beatriz Pereira, tutora y curadora de sus hijos, y Simón de Pereira, su marido difunto, y los demás interesado en los bienes y herencia de Simón y Lorenzo Pereira. Aprox. 1640. s/l. BNE, Porcones, 123 (7).

Ediciones Universidad de Salamanca / @®@@ Stud. his., H. ${ }^{a}$ mod., 42, n. 2 (2020), pp. 255-288 
JAVIER GÓMEZ MESAS

LOS PEREIRA, CARDOSO Y LADRÓN DE GUEVARA: TRES FAMILIAS ESPECIALIZADAS

EN EL ABASTECIMIENTO DE PERTRECHOS Y BASTIMENTOS NAVALES EN EL REINADO DE FELIPE IV

represión inquisitorial lusa y a las nuevas posibilidades económicas que ofrecía la unión (Aguado de los Reyes, 2005: 135-1640).

La mayor parte de los recién llegados se instalaron en alguna de las cuatro collaciones próximas al centro de la ciudad -San Salvador, la Iglesia Mayor, Santa Cruz y la Magdalena-, valiéndose de aquellos familiares, clientes o amigos que tenían experiencia previa en el territorio (Stundicki-Gizbert, 2007: 55-60) ${ }^{6}$. En estos barrios, la familia era la unidad constitutiva a partir de la cual se gestaban extensas comunidades con rasgos culturales similares que convergían en espacios de sociabilidad comunes como la Capilla de San Antonio de los Portugueses (Berajano Pellicer y García Bernal, 2018: 380-400). Una vez instalados en la ciudad hispalense, los Pereira desarrollaron una intensa labor mercantil que les ofreció el rédito suficiente para desarrollar tratos crediticios con la Corona y trasladarse a Madrid. Entre 1626-1629, los hermanos Simón y Lorenzo ejercieron como tesoreros de la hermandad de San Antonio de los Portugueses por tres años lo que probaba una gran capacidad crediticia al gestionar las cuentas de la hermandad y adelantar el capital necesario para cubrir sus gastos (Pulido Serrano, 2014: 46).

El primer asiento que ambos hermanos realizaron en Madrid se concertó el 9 de abril de 1625 . Simón y Lorenzo Pereira se comprometieron a poner 12.000 escudos de 57 placas en Amberes para cubrir los gastos de la embajada del Conde de Gondomar de los años 1625 y 1626 (Marcos Martín, 2001: 31; Carlos Morales, 2019: 163) 7 . En virtud de este asiento, ambos hermanos obtuvieron la administración al por mayor de las salinas del reino entre 1626-16318.

La irrupción definitiva de los Pereira en los asientos de provisiones generales se produjo tras la declaración de suspensión de pagos del 31 de enero de 1627 y el concierto del medio general el 17 de septiembre de dicho año. Entonces, la Corona fomentó la concurrencia de nuevos activos financieros capaces de sostener los gastos de la monarquía hispánica (Domínguez Ortiz, 1960: 20-34; Elliot, 2012: 304-309; Herrero Sánchez, 2005: 115-125) ${ }^{9}$. Los hombres de negocios portugueses, vecinos de dudosa condición religiosa, se convirtieron en los candidatos idóneos dada su

6. Vemos como estos patrones se repiten en otros espacios como Madrid. Miguel de León, un comerciante de telas, vivía junto a su mujer en la calle de la Cruz de Madrid junto a un mozo llamado Francisco Gravel, corredor de lonja, y dos hermanos suyos que vinieron directamente de Portugal para controlar la distribución de telas al por menor. Testimonio de Miguel de León. 05/04/1652. Madrid. AHN, Inquisición, leg. 1896, exp. 18, fol. 6 r-7 v.

7. Hemos empleado la documentación AGS, Contadurías Generales, leg. 119-2, citada en las obras referenciadas.

8. AGS, CMC, $3^{\text {a }}$ época, leg. 1746, núm. 9.

9. El creciente descrédito de los hombres de negocios genoveses coincidió con la escisión de la sociedad ligur entre los que apoyaban la tradicional alianza con la Monarquía Hispánica y aquellos que defendían la autonomía republicana.

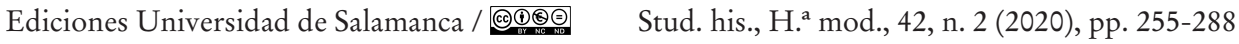


presencia en las principales plazas económicas y la probada solvencia de su capacidad crediticia, tal y como afirmaba Duarte Gómez Solis «porque prudencia en mercader rico y que lo pueda ser en todas las plazas con dedos de papel, en razón del crédito, solamente se hallara en un portugués honrado» ${ }^{10}$.

El mismo año de la suspensión de pagos, 1627, Duarte Fernández, Manuel de Paz, Simón Suárez, Manuel Rodríguez de Elvas, Nuño Díaz Méndez Brito -hermano de Francisco Díaz Méndez y cuñado de los Pereira-, los hermanos Pereira y su socio Juan Núñez Saravia negociaron un asiento de provisiones a través de la Junta del Donativo destinado a sostener el ejército de Flandes y la Armada del Mar Océano. Las negociaciones con los distintos grupos de hombres de negocios discurrieron en salas contiguas. Los portugueses se emplazaron en la Sala Nueva del Alcázar, donde las presiones de la Corona y las exacerbadas pujas de los lusos guiaron las conversaciones entre las partes (Sanz Ayán, 2013: 55; Ebben, 1993: 541-550). Finalmente, el valor global del asiento ascendió a 1.179.999 escudos de plata castellanos, aunque, tras la retirada de Nuño Diaz Méndez Brito, el montante ofrecido se redujo al millón escaso (Marcos Martín, 2001: 32-34; Carrasco Vázquez, 2004: 284).

A cambio del ofrecimiento económico a la Corona, los miembros de la naçao portuguesa recibieron prerrogativas que protegían sus intereses mercantiles y garantizaban su protección. Así, la Corona designó un alcalde de casa y corte encargado de gestionar los contratiempos en los asientos de los portugueses y proteger sus intereses (García Montón, 2015, 75-112). Igualmente, los delitos de fe fueron perdonados por un periodo de tres meses tras la emisión de una carta regia el $26 \mathrm{de}$ junio de 1627. Un año después, el 11 de marzo de 1628, los portugueses obtuvieron amplias garantías judiciales ante el Santo Oficio luso al prohibirse las detenciones arbitrarias por falsa acusación y el desarrollo del proceso judicial de forma pública (López Salazar Codes, 2010: 263-268).

Con el afianzamiento del colectivo luso en las finanzas generales del reino, los servicios pecuniarios de los hermanos Pereira mostraron gran continuidad. Tras el suceso de Matanzas en 1628, la Corona tenía una escasa capacidad crediticia para afrontar el pago del nuevo ejército de Ambrosio Spinola destinado a Mantua y la defensa de Flandes. Dada la gravedad de la situación, Olivares procedió a la incautación de 1.000 .000 de ducados de plata consignados en la flota de 1629 y aumentó en un 5\% la Avería. Las nuevas consignaciones de los damnificados, entre las que se encontraban las de los Pereira, se situaron en juros sobre los Millones de varias ciudades españolas (Díaz Blanco, 2012: 124-127). Un año después, los hermanos Pereira sufragaron una pequeña parte de los gastos secretos de la Corona al ofrecer

10. Gomez Solis, Alegación en fauor de la Compañia de la India Oriental, 1628, fol. 283-284. Consultado en Biblioteca Histórica Marqués de Valdecilla: BH DER 6729.

Ediciones Universidad de Salamanca / @®@@ Stud. his., H. ${ }^{a}$ mod., 42, n. 2 (2020), pp. 255-288 
JAVIER GÓMEZ MESAS

LOS PEREIRA, CARDOSO Y LADRÓN DE GUEVARA: TRES FAMILIAS ESPECIALIZADAS

EN EL ABASTECIMIENTO DE PERTRECHOS Y BASTIMENTOS NAVALES EN EL REINADO DE FELIPE IV

400 ducados de vellón de sus provisiones para la Armada del Mar Océano (Seiz Rodrigo, 2010: 187-190).

Gracias a la distribución de varios de sus allegados en rentas estratégicas como los puertos secos y los almojarifazgos, la casa de negocios pudo controlar los puestos de entrada y salida de mercancías. En consecuencia, los Pereira obtuvieron una reducción significativa de los gravámenes impuestos a determinadas mercancías y pudieron, posiblemente, desarrollar actividades ilícitas dada su vinculación con varias casas implicadas en casos de contrabando (Carrasco Vázquez, 2004: 210-219, 268-272) ${ }^{11}$.

A la muerte de los hermanos Simón y Lorenzo Pereira en 1631, la sucesión de la casa de negocios recayó en un destacado hombre de negocios proveniente de Lisboa que era cuñado de los recién fallecidos: Alfonso Cardoso. Al poco tiempo de heredar la casa de los Pereira, Alfonso Cardoso tuvo que hacer frente a diferentes pleitos con el antiguo socio de los Pereira: Juan Núñez Saravia. El origen de la disputa fue un supuesto impago que los Pereira no habían abonado a Saravia cuando ambas partes tenían tratos en común (Carrasco Vázquez, 2004: 495-511) ${ }^{12}$.

Antes de su instalación definitiva en Castilla, los Cardoso habían sido una familia de reconocido prestigio asociada a la ruta comercial Goa-Lisboa y la trata de esclavos negros africanos. Con sede en Lisboa, la casa de negocios de los Cardoso, vinculada al capital sefardita, contó con el acceso directo a las reservas de diamantes de la India, y gracias a sus sólidos enlaces gozó del beneplácito de los intermediarios locales que terciaban en el intercambio de diamantes por eslavos (Hofmeester, 2018: 70-73). Tras su extracción, los diamantes seguían dos destinos: o eran intercambiados por esclavos negros africanos que tras su paso por Lisboa o Sevilla eran enviados al Nuevo Mundo, o bien eran remitidos a Flandes para su talla y posterior redistribución como bienes suntuosos en los principales mercados europeos y americanos (Newson y Michin, 2007: 45-78). Hasta su muerte en 1639, Alfonso Cardoso se convirtió en uno de los principales distribuidores de diamantes en la península ibérica, teniendo como clientes miembros de la nobleza castellana.

Entre sus clientes más habituales destacamos la casa nobiliaria de los Tassis. En el primer tercio del siglo XVII, la casa se encontraba altamente endeudada por el excesivo gasto suntuoso asociado a la compra de joyas y diamantes. En virtud de estos apuros financieros, el primer conde de Villamediana, Juan de Tassis y Peralta,

11. Ruy Fernández Pereira, pariente de Simón y Lorenzo Pereira, arrendó junto a Pedro Gómez Reinel, el almojarifazgo mayor de Indias. En las primeras décadas del siglo XVII, Diego Pereira, Juan Núñez Saravia y otros mercaderes portugueses habían sido acusados introducir moneda falsa procedente de las cecas de Holanda a través del suroeste de Francia.

12. Según el propio Juan Núñez Saravia, los largos pleitos con Alfonso Cardoso habían afligido su salud. Testamento de Juan Núñez. 13/01/1639. Madrid. AHPNM, leg. 4.017, fol. $12 \mathrm{r}-13 \mathrm{r}$. 
enajenó a perpetuidad el oficio de correo mayor de Plasencia a Antonio Picardo en 1622. El precio de venta se fijó en 19.000 ducados de plata, 15.000 ducados abonados al contado en concepto de principal, y otros 4.000 ducados de plata que debían ser pagados en un plazo de 10 meses. Por iniciativa del conde, Alfonso Cardoso adelantó los 4.000 ducados de plata y emitió una escritura otorgada el 25 de mayo de $1622^{13}$.

Tras el fallecimiento de Juan de Tassis, el 22 de agosto de 1623, los bienes de la casa nobiliaria fueron embargados con el fin de saldar las deudas pendientes con los acreedores. Según las cuentas del difunto, Antonio Picardo aparecía como deudor de 4.000 ducados de plata, adelantados por Alfonso Cardoso. Sin embargo, Picardo argumentaba haber satisfecho la deuda a través de una carta de pago del 18 de agosto de 1623. Las desavenencias entre ambas partes dieron lugar a un pleito.

En el auto de vista del pleito, el alcalde Pedro Díaz Romera entendió que la suma, supuestamente adeudada por el oidor, no había sido saldada y ejecutó los bienes y la hacienda de Picardo ${ }^{14}$. Ante este agravio, el oidor presentó distintas alegaciones por las que debían eximirle del pago de los 4.000 ducados y retirar el embargo que pesaba sobre sus bienes. Según Picardo, el conde de Villamediana nunca recibió los 4.000 ducados de Alfonso Cardoso. En su lugar, el noble y el hombre de negocios habrían elaborado una escritura falsa con la que pretendían compensar las cuantiosas deudas que la casa nobiliaria mantenía con el portugués por valor de joyas y diamantes. De este modo, Alfonso Cardoso podría cobrar 4.000 ducados de plata, una vez se produjese la muerte del conde, y se procediese al saldo de las deudas con los acreedores. Tal y como alegaba Antonio Picardo en:

La verdad es que ni el, ni el conde los recibió de Alfonso Cardoso [...] pues aquí no hubo paga que volver a recobrar, sino simulación y embeleco para huir Cardoso del pleito de acreedores donde parecía imposible cobrar lo que el conde le debía en joyas y diamantes, entrando en tan flaco derecho a competir con acreedores más antiguos y de mejores causas $[\ldots]^{15}$.

La casa de negocios de los Cardoso implantó una estrategia inversora múltiple que mostró cierta continuidad con los asuntos legados por los Pereira. Por consiguiente, Diego y Alfonso Cardoso se hicieron cargo de la administración de las

13. Por el Doctor Antonio Pichardo Oidor de Valladolid, con Alfonso Cardoso vecino de Madrid sobre la apelación de la sentencia de pleito de acreedores y venta de oficios. BNE, Porcones, 18/39. Para ver los pormenores de la compra, fol. $1 \mathrm{r}-6 \mathrm{v}$.

14. Por el Doctor Antonio Pichardo Oidor de Valladolid, con Alfonso Cardoso vecino de Madrid sobre la apelación de la sentencia de pleito de acreedores y venta de oficios. BNE, Porcones, 18/39, fol. 6 r- $10 \mathrm{v}$.

15. Extracto de la alegación número 45 presentada por Antonio Picardo. Por el Doctor Antonio Pichardo Oidor de Valladolid, con Alfonso Cardoso vecino de Madrid sobre la apelación de la sentencia de pleito de acreedores y venta de oficios. BNE, Porcones, 18/39, fol. $25 \mathrm{r}$.

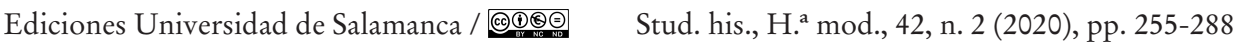


JAVIER GÓMEZ MESAS

LOS PEREIRA, CARDOSO Y LADRÓN DE GUEVARA: TRES FAMILIAS ESPECIALIZADAS

EN EL ABASTECIMIENTO DE PERTRECHOS Y BASTIMENTOS NAVALES EN EL REINADO DE FELIPE IV

salinas de los partidos de Andalucía de «Tierra Adentro», Andalucía costa de la mar, Granada, Badajoz, Atienza y Espartinas (Sanz Ayán, 1998: 38). Igualmente, ambos hermanos concurrieron en los asientos de provisiones generales, aunque sus principales inversiones se orientaron a los contratos de abastecimiento naval junto a los Ladrón de Guevara.

\section{LA GESTACIÓN DE LA COMPAÑÍA CARDOSO-LADRÓN DE GUEVARA (1632-1642)}

En virtud de los vínculos locales de los Ladrón de Guevara con las élites mercantiles navarras y del norte peninsular, la casa distribuyó múltiples agentes en los resguardados puertos del Cantábrico y las inmediaciones navarras. Ello permitió a la compañía desempeñar una intensa actividad mercantil con la que maximizar los beneficios que reportaba el trato mercantil a gran escala e introducir pertrechos procedentes de Francia y Holanda, haciendo uso de las licencias especiales o vinculados, probablemente, al contrabando ${ }^{16}$.

La asociación Cardoso-Ladrón de Guevara tenía un objetivo fundamental: monopolizar los abastos y operaciones de puesta a punto de las distintas unidades navales de la Corona. Para sellar una alianza económica que implicaba la fusión de sus redes comerciales, los jefes de ambas casas de negocios, Martín Ladrón de Guevara y Alfonso Cardoso, concertaron un matrimonio entre Diego Cardoso y una hija de Martín, posiblemente Fernanda Ladrón de Guevara. Desde entonces, las dos familias, una de origen navarro y otra judeoconversa, concurrieron bajo la misma firma. Matrimonios cruzados, como el de los Ladrón de Guevara y Cardoso, invitan al lector a reflexionar acerca de la endogamia del colectivo sefardita, pues en pro de un beneficio socio-económico las uniones con cristianos viejos podían llegar a producirse (Sánchez Durán, 2018: 214-226; Stundicki- Gizbert, 2007: 73-76)17.

Mientras estuvo vigente la guerra económica entre la Corona y las Provincias Unidas a partir de 1621, y Francia desde 1635, la compañía mostró una gran continuidad en las provisiones efectuadas valiéndose de las nuevas rutas comerciales

16. En la negociación de sus asientos, la compañía trató de obtener cobertura legal en sus tratos con el eje atlántico. En el asiento para el apresto y carena de 35 bajeles y la provisión de pertrechos y bastimentos para la escuadra San Joseph de 1643, la Corona concedió a la compañía la posibilidad de comerciar con los holandeses y transportar pertrechos en navíos holandeses y franceses. De esta forma, el comercio con mercancías prohibidas fruto de la prohibición mercantil con las Provincias Unidas, considerado contrabando, era reconocido ante la imperiosa necesidad de determinados pertrechos. AGMM, Depósito Histórico, leg. 43, fol. $31 \mathrm{v}$.

17. Ambos autores han puesto de evidencia, la existencia de estos matrimonios y la necesidad historiográfica de poner de relieve la existencia de matrimonios mixtos entre judeoconversos y cristianos.

Ediciones Universidad de Salamanca / @®@@ Stud. his., H. ${ }^{a}$ mod., 42, n. 2 (2020), pp. 255-288 
JAVIER GÓMEZ MESAS

LOS PEREIRA, CARDOSO Y LADRÓN DE GUEVARA: TRES FAMILIAS ESPECIALIZADAS

EN EL ABASTECIMIENTO DE PERTRECHOS Y BASTIMENTOS NAVALES EN EL REINADO DE FELIPE IV

abiertas por la diplomacia hispánica. A pesar de las dificultades inherentes al estado de guerra y la obstrucción de determinados canales de distribución, la eficiente y operativa cadena de agentes repartidos en múltiples puntos estratégicos, así como los abundantes medios materiales y económicos a disposición de la compañía, garantizaron el intercambio global de mercancías y el suministro de útiles navales provenientes del Mar del Norte.

Ante la reanudación de las hostilidades en Flandes, la Corona se planteó dos alternativas posibles: la continuación de la guerra o el concierto de una paz honrosa que favoreciese el comercio de ambas partes. De una parte, el general Ambrosio Spinola defendía un armisticio que mejorase las condiciones fijadas en la Tregua de los Doce Años (1609-1621). Por el contrario, el Conde Duque, apoyado por el embajador Gabriel de Roy, era partidario de tejer alianzas diplomáticas con las potencias católicas del norte de Europa con el ánimo de llevar a cabo un plan de rearme naval que subyugase el poderío mercantil rebelde (Elliot, 2012: 350-363). Finalmente se impuso la propuesta del Conde Duque.

El balance de la estrategia del valido no fue satisfactorio. En el plano diplomático primó el interés particular de cada entidad política frente a un hipotético objetivo común: los mercantes y armadores flamencos argumentaban un menoscabo a sus privilegios mercantiles; mientras los polacos acordaban la paz con Suecia y la Hansa recelaba de las pretensiones hispánicas en el Báltico. Asimismo, la falta de numerario y el bloqueo de los puertos flamencos lastraron el proyecto de rearme naval, a pesar del incremento del corso flamenco (Stradling, 1992: 96-100; Alcalá Zamora, 1975: 270-275).

Con la reanudación de la guerra en Flandes, la logística militar adquirió una relevancia superlativa para garantizar el trasvase de unidades navales y remitir el capital y los víveres necesarios a los lugares del conflicto. Por tierra, el camino español quedó bloqueado tras la toma de Lorena por los franceses en 1634 y la única alternativa terrestre pasaba por atravesar los inestables estados alemanas. Fue entonces cuando el mar se convirtió en la única vía posible para allegar los recursos desde la península a Flandes (Parker, 1985: 107-113). La vía marítima era más rápida aunque también más costosa, así, desde los puertos de A Coruña, Laredo o San Sebastián, los barcos cargados de víveres y tropas partían escoltados, habitualmente, por alguna unidad de la Armada de Flandes, y tras bordear la costa francesa y el canal de la Mancha, alcanzaban Flandes (Alcalá Zamora, 1975: 346-356).

Una ruta marítima complementaria apareció tras la alianza hispano-inglesa de 1630: la vía Dover. Desde Andalucía, las naos cargadas de hombres, enseres y plata americana navegaban con destino a Dover bordeando la costa francesa. Una vez las flotas se hallaban en el puerto inglés, la plata se descargaba y se remitía a Londres para su acuñación. A cambio del metal y sustanciosas comisiones, los ingleses garantizaban la reexportación de los enseres bélicos a Flandes (Taylor, 1972, 240, 243-247;

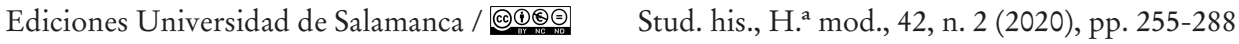


JAVIER GÓMEZ MESAS

LOS PEREIRA, CARDOSO Y LADRÓN DE GUEVARA: TRES FAMILIAS ESPECIALIZADAS

EN EL ABASTECIMIENTO DE PERTRECHOS Y BASTIMENTOS NAVALES EN EL REINADO DE FELIPE IV

Ruiz Martín, 1990: 248-252). Hasta el estallido de la guerra civil inglesa, hombres de negocios como Benjamin Wright aprovecharon estos cauces para desarrollar lucrativos negocios en los que participó la compañía Cardoso- Ladrón de Guevara, que contó con una vía alternativa para importar las mercancías del Báltico (Alloza Aparicio y Zofío Llorente, 2013: 673-675).

Ante la necesidad imperante de suministros navales para sostener la ingente maquinaria naval hispánica, la Corona sopesó varias alternativas, entre las cuales podemos destacar la emisión de licencias especiales por el Almirantazgo flamenco a mercaderes holandeses (Rodríguez Grajera, 2015, 961-973). La medida no gozó de una gran continuidad en el tiempo y fue entonces cuando el capital portugués se convirtió en el principal intermediario entre la comunidad mercantil holandesa y la Corona (Sanz Ayán, 2004, 95-97). Entre ellos, la compañía Cardoso-Ladrón de Guevara ejerció una importante labor de mediación entre el capital holandés, necesitado de la sal peninsular, y el poderío naval hispano que precisaba enseres navales del Mar del Norte. Gracias a una extensa plantilla integrada por agentes y corresponsales que radicaban en múltiples puntos estratégicos, el cometido era viable. Desde estos enclaves, los empleados de la compañía controlaban el trato a nivel local, accediendo a ciertas mercancías con gran mercado exterior, gestionaban el capital de la compañía y garantizaban el intercambio general de productos. Del mismo modo, las adehalas y facultades negociadas garantizaban las transacciones y sacas de moneda.

En 1631, los hermanos Diego y Alfonso Cardoso, en nombre de la compañía, firmaron un asiento para el suministro de los bastimentos y pertrechos requeridos para la Armada del Mar Océano por un periodo cinco años. El valor del asiento fue de 1.500.000 ducados de vellón a razón de 300.000 ducados de vellón/año: 200.000 por valor de bastimentos y los 100.000 restantes de pertrechos ${ }^{18}$. Las consignaciones se situaron en efectos relativamente seguros, como las remesas indianas (40.000 ducados [13’33\%]); la renta de la sal del partido de Sevilla (140.000 ducados [46’67\%]); el derecho de la sal de la costa de la mar de Andalucía (100.000 ducados [33’33\%]); y al contado $(20.000 \text { ducados [6'6\%] })^{19}$.

En cuanto a los bastimentos, el bizcocho debía importarse de Sicilia o Berbería, y el vino de Málaga, Jerez o el Puerto de Santa María. Ambos géneros debían remitirse a la bahía de Cádiz en el mes de abril. La compañía cubría todos los gajes de transporte e intendencia. Únicamente, la Real Hacienda sufragaría el coste de los suministros en caso de que estos se hubiesen corrompido a los dos meses de

18. Asiento de Diego y Alfonso Cardoso para la provisión de pertrechos y bastimentos a la Armada del Mar Océano (1632-1636). 22/05/1632. Madrid. AGMM, Depósito Histórico, Libro 35, fol. 6 r-16 r. Cláusulas 2 y 3.

19. Ibidem, Cláusulas 23, 24, 25, 27.

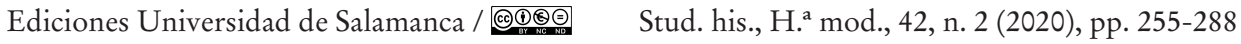


JAVIER GÓMEZ MESAS

LOS PEREIRA, CARDOSO Y LADRÓN DE GUEVARA: TRES FAMILIAS ESPECIALIZADAS

EN EL ABASTECIMIENTO DE PERTRECHOS Y BASTIMENTOS NAVALES EN EL REINADO DE FELIPE IV

haberse producido la entrega ${ }^{20}$. En lo referente a los pertrechos: la jarcia en cáñamo debía proceder de Sevilla, Calatayud o Nápoles ya alquitranada. En tanto que los cables y ajustes debían ser confeccionados en Sevilla. Todos los pertrechos debían entregarse en el puerto de Lisboa, donde la casa de negocios contaba con almacenes y puertos propios ${ }^{21}$.

Entre las facultades negociadas, destacamos una licencia de saca por valor de 68.000 ducados en oro o plata para el primer año del asiento. Además, mientras el asiento estuviese en vigor, los asentistas podían reclamar la expedición de cuantas licencias especiales fuesen menester para garantizar el acopio de mercancías ${ }^{22}$. En concepto de adehalas, Alfonso Cardoso recibió el título de Tesorero de la renta de la sal de la Costa del Mar por tiempo de cinco años ${ }^{23}$.

Un año después de haber sido aprobado el asiento, 1632, las libranzas por

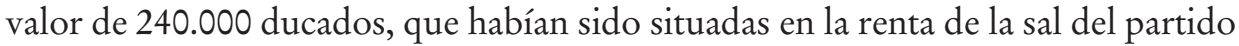
de Sevilla y el derecho de la sal de la costa de Mar de Andalucía, se mudaron a los derechos de la sal de los partidos de Andalucía Tierra Adentro, Granada y Badajoz. En compensación por estas modificaciones, los Cardoso obtuvieron el título de tesorero en todos estos partidos y percibieron el caudal procedente del precio de la sal entre agosto de 1632 y finales de diciembre del mismo año. Como tesoreros, Diego y Alfonso Cardoso estaban obligados a entregar una relación mensual con un tanteo de las libranzas emitidas por cuenta de los juros situados en las salinas ${ }^{24}$. En la gestión e intendencia de la administración de estas rentas, un joven llamado Ventura Donis comenzó a ganar protagonismo, una experiencia que sin duda le sirvió para convertirse en uno de los principales financieros a partir de la década de 1650 (Sanz Ayán, 1998: 40-42; 1989: 190-193).

En 1633, Alfonso Cardoso suscribió un nuevo asiento por el que se comprometió a suministrar los bastimentos y pertrechos necesarios para la capitana y almiranta de la flota de Nueva España de $1634^{25}$. Un año después se comprometió a suministrar pertrechos por valor de 55.000 ducados para cuatro navíos ${ }^{26}$.

20. Ibidem, Cláusulas 4,8.

21. Ibidem, Cláusula 18.

22. Ibidem, Cláusula 15.

23. Ibidem, Cláusula 26.

24. Cédula Real para el traslado de las consignaciones situadas en la renta de la sal del partido de Sevilla y el derecho de la sal de la costa de Mar de Andalucía. 31/12/1632. Madrid. AGMM, Depósito Histórico, lib.35, fol. 58 r-60 r.

25. Carta de Fernando Ruiz de Contreras al Conde de Peñaflor sobre el asiento de Alfonso Cardoso. 26/12/1633. Madrid. AGI, Indiferente, leg. 2499, libro 15, fol. 283 v-286 r.

26. Carta de Fernando Ruiz de Contreras al señor Pedro Vibanco respondiendo a unas cartas precedentes. 23/01/1635. Madrid. AGI, Indiferente, leg. 2500, lib. 16, fol. $196 \mathrm{v}-197 \mathrm{v}$.

Ediciones Universidad de Salamanca / @®@@ Stud. his., H. ${ }^{a}$ mod., 42, n. 2 (2020), pp. 255-288 
JAVIER GÓMEZ MESAS

LOS PEREIRA, CARDOSO Y LADRÓN DE GUEVARA: TRES FAMILIAS ESPECIALIZADAS

EN EL ABASTECIMIENTO DE PERTRECHOS Y BASTIMENTOS NAVALES EN EL REINADO DE FELIPE IV

Asimismo la compañía concurrió en el aprovisionamiento y sostén de la escuadra de galeras de España. La mayor parte de las operaciones en este sector se realizaron por vía de factoría, así, Martín Ladrón de Guevara ejerció como factor de galeras de la escuadra de galeras de España desde 1632 hasta 1637, e inmediatamente después Alfonso Cardoso hizo lo propio en los cinco años sucesivos. Sin embargo, la muerte de Alfonso Cardoso en 1639 hizo que la factoría pasase a manos de Fernando Ladrón de Guevara: el heredero de la casa de negocios de los Cardoso (Sanz Ayán, 1989: 34, 35; 2013: 26-28) (Álvarez Nogal; 2012: 30-34).

En la escuadra de galeras de España, la aparición de los factores respondió a la voluntad de la administración regia por limitar las corruptelas llevadas a cabo por los oficiales reales, más concretamente el proveedor, y garantizar el abastecimiento de pertrechos y bastimentos. De hecho, el factor de galeras adquirió plena potestad en todo lo referente al aprovisionamiento de pertrechos y bastimentos y el mantenimiento de las tropas de galeras (Marchena Giménez, 2010: 60, 79, 133-135). Anualmente, el factor realizaba una cuenta general en la que inclúa los desembolsos, ordinarios y extraordinarios efectuados para la compra de enseres navales o suministros. Una vez la relación estaba concluida pasaba a la Contaduría Mayor de Cuentas, encargada de fiscalizar la actividad del factor, y al Consejo de Guerra ${ }^{27}$.

En 1632, Martín Ladrón de Guevara negoció una factoría por la que se comprometió a suministrar bastimentos, pertrechos y municiones a doce galeras de la escuadra de España durante cinco años. El valor total de las provisiones ascendió a 69.592.275,25 maravedís de plata; un 75,33\% por valor de bastimentos $(52.423 .860$ maravedís de plata) y un $24,47 \%$ por pertrechos y municiones (17.029.229 maravedís de plata ${ }^{28}$. Todas las mercancías se debían entregar en el Puerto de Santa María o allá donde invernasen las galeras. En caso de ser necesarias más provisiones, el factor debía ser avisado con un mes de antelación y estaba obligado a ofrecer las mercancías al mismo precio que había expresado en las cláusulas de la factoría. Si esto sucedía en alta mar, los oficiales de galeras debían hacer una relación de los gastos extraordinarios que se sucedieren durante la marcha, y posteriormente remitirla al factor para que efectuase los desembolsos correspondientes ${ }^{29}$. Entre las principales facultades negociadas, destacamos dos licencias de saca: una para extraer 20.000

27. Durante la factoría de Alfonso Cardoso, el rey permitió la inclusión de los gajes del sustento y vestimenta de los forzados destinados a galeras en las cuentas de la factoría. Cédula Real para que en la cuenta del factor de galeras Alfonso Cardoso se reciba y haga efectivo todo lo dado y gastado. 07/11/1638. Madrid. AGMM, Depósito Histórico, lib. 40, fol. 283 r-283 v.

28. Asiento de galeras entre el rey y Martín Ladrón de Guevara. 28/01/1632. Madrid. AGS, Guerra Antigua, leg. 1072. Cláusula 1 y 2.

29. Ibidem, Cláusula 2 y 3.

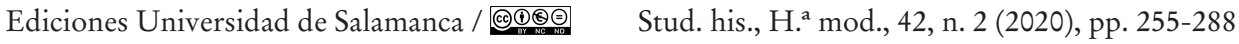


JAVIER GÓMEZ MESAS

LOS PEREIRA, CARDOSO Y LADRÓN DE GUEVARA: TRES FAMILIAS ESPECIALIZADAS

EN EL ABASTECIMIENTO DE PERTRECHOS Y BASTIMENTOS NAVALES EN EL REINADO DE FELIPE IV

fanegas de trigo de las plazas de Orán y Mazalquibir, y otra para poder sacar 30.000 ducados de plata/año y realizar compras en el extranjero ${ }^{30}$.

Entre 1637-1639, Alfonso Cardoso sucedió a Martín Ladrón de Guevara en la factoría de galeras. El portugués ostentó la plaza hasta su muerte, cuando fue sustituido por Fernando Ladrón de Guevara que pasó a encargarse de la gestión de la escuadra de galeras de España entre 1639-1642. Valiéndose de su condición de factor de galeras, Alfonso Cardoso llevó a cabo un lucrativo negocio: la exportación de metal americano a Italia, a cambio de manufacturas y trigo procedente de Sicilia, todo ello transportado en la escuadra de las galeras de España que el mismo gestionaba (Álvarez Nogal, 1997: 33-38)31. A raíz de la sublevación de Barcelona en 1640, la factoría de galeras quedó gravemente perjudicada. Tres de las galeras aviadas por Alfonso Cardoso, fueron destruidas y sus consignaciones quedaron paralizadas. Todavía en 1645 Fernando Ladrón de Guevara continuaba reclamando el pago de las consignaciones adeudadas ${ }^{32}$.

Para el correcto desarrollo del negocio estrella de la compañía, las inversiones navales, la compañía ideó una planificación mercantil compleja que incluía operaciones de diversa índole como el arrendamiento de rentas estratégicas, la adquisición de oficios vinculados con la gestión de mercancías y la obtención de licencias especiales. Entre todas las rentas, la administración de las salinas fue la más importante para la compañía al garantizar el acceso a la sal, bien tan demandado por las salazones y queserías del eje atlántico. A cambio del suministro de sal, la compañía obtenía los pertrechos y el grano del Báltico necesarios para el cumplimiento de las factorías y asientos navales (Sanz Ayán, 1992: 915-918; Rodríguez Grajera, 2015: 1271-1285). Asimismo, con el control de ciertas aduanas y rentas que gravaban los bienes de consumo, tenían acceso directo a los centros de producción de fabricación de bastimentos para las flotas: vino, trigo, bizcocho, garbanzos, habas, bacalao, tocino, etc. ${ }^{33}$.

En 1637, Martín Ladrón de Guevara adquirió los derechos del primer y cuarto uno por ciento del Puerto de Santa María a través de un asiento de anticipación de 7.331 ducados, 8 reales y 3 maravedíes (Diaz Blanco, 2009: 73-77). Seis años después, en virtud de una adehala negociada en un asiento de provisión de 200.000

30. Ibidem, Cláusula 16 y 17.

31. A lo largo de la década Alessandro Pallavicino se convirtió en un importante asentista de provisiones generales y sus consignaciones se situaron en efectos seguros. En 1648, el genovés percibió 400.000 ducados de plata -100.000 de ellos en la Corte- del caudal procedente en la flota del general Antonio de Isasi. Libranza a Alejandro Palavesin. 19/05/1648. Madrid. AGI, Contratación, 4948.

32. Cuentas de Fernando Ladrón de Guevara como administrador de la casa de Alfonso Cardoso. 21/08/1645. Madrid. AHN, Hacienda, lib.7890, fol.190.

33. Para conocer en profundidad la confección y transporte de pertrechos remitimos a Mena-García: 2004, 447-484. 
JAVIER GÓMEZ MESAS

LOS PEREIRA, CARDOSO Y LADRÓN DE GUEVARA: TRES FAMILIAS ESPECIALIZADAS

EN EL ABASTECIMIENTO DE PERTRECHOS Y BASTIMENTOS NAVALES EN EL REINADO DE FELIPE IV

escudos, recibió el oficio de fiel y medidor mayor de Sevilla y sus lugares, exceptuando Écija, Cazalla y Carmona, donde previamente ya se había vendido el cargo a perpetuidad. El oficio incluía una renta de cuatro maravedíes por arroba de vino y aceite tasada (Sanz Ayán, Recuperado de http://dbe.rah.es/biografias/90242/ martin-ladron-de-guevara).

Con el fin de garantizar el acopio de enseres navales, la compañía empleó licencias especiales o de contrabando. Estas podían ser adquiridas directamente a la Corona, incluidas como facultades de los asientos, o bien compradas a otros hombres de negocios en un mercado de segundo orden ${ }^{34}$. Sus poseedores podían importar o exportar mercancías por un valor determinado en un tiempo limitado. A cambio, la Corona garantizaba el acopio de «mercancías prohibidas», sin quebrantar de manera oficial la prohibición mercantil, y además obtenía ingresos extraordinarios para la Real Hacienda. Por el contrario, el principal riesgo al que debía hacer frente la Corona era el fraude. Era práctica frecuente que algunos hombres de negocios excediesen las cuantías permitidas o introdujeran géneros diversos a los expresados en las licencias con un afán especulativo (Alloza Aparicio, 2003: 227-235).

Durante el periodo de existencia de la compañía, la obtención de licencias fue constante. En 1635, la declaración de guerra de Francia a la Corona se tradujo en la incautación de los bienes comercializados por los franceses en territorio peninsular e impuso trabas a la libre concurrencia de géneros y mercaderes franceses (Alloza Aparicio, 2006: 77-147). Ello afectó a la comercialización de pertrechos procedentes del reino vecino, de modo que la Corona, necesitada de velas y cuerdas, concedió licencias especiales para garantizar su adquisición entre 1636-1638. Por ende, la compañía obtuvo dos licencias: Martín Ladrón de Guevara y Diego Cardoso podían introducir géneros franceses por valor de 350.000 ducados y Alfonso Cardoso contaba con una licencia de 50.000 ducados $^{35}$.

Para afrontar las compras en el exterior y sostener la logística mercantil, la compañía implantó un eficiente sistema de pagos fundado en el endoso de deudas entre los distintos agentes que radicaban en puntos estratégicos, desde donde

34. Los Cardoso concurrieron en este mercado de segundo orden. En diciembre de 1644, Martín Ladrón de Guevara adquirió una licencia especial por valor de 150.000 ducados para importar mercancías procedentes de Holanda y Francia. Asimismo vendió 9.783.376 maravedíes de plata de una licencia de 33.388.400 maravedíes de plata a Juan Urit. Libro registro de licencias de contrabando. 03/01/1645. Madrid. AGMM, Depósito Histórico, leg.42, fol. 178 r.

35. AGS, Contaduría del sueldo. $1^{\circ}$ serie, legajo 159. En 1645, Duarte de Acosta, aprendiz de la compañía, adquirió una licencia que le brindaba la posibilidad valor de 15.000 ducados de plata a cambio de 1.000 ducados de plata. Esta le ofrecía la posibilidad de introducir velas y otros géneros franceses por dos años. Traslado del asiento de permisión de mercaderías de contrabando que este año se hizo con el señor Don Juan de Góngora. 01/01/1645. Madrid. AHN, Inquisición, leg. 4378, número 79. 
JAVIER GÓMEZ MESAS

LOS PEREIRA, CARDOSO Y LADRÓN DE GUEVARA: TRES FAMILIAS ESPECIALIZADAS

EN EL ABASTECIMIENTO DE PERTRECHOS Y BASTIMENTOS NAVALES EN EL REINADO DE FELIPE IV

informaban sobre cuestiones relativas al status quo de los mercados financieros, precios y cambios monetarios. Desde estos espacios, los agentes giraban letras de cambio entre sí, acumulando de forma progresiva la deuda de la compañía hasta que se saldaba íntegramente en una plaza determinada (Boyajian, 1983: 70-85). La principal ventaja que ofrecía este sistema era un mayor dinamismo a las transacciones financieras, pues el empleo de las letras de cambio reducía la duración y los costes asociados al transporte del dinero. Además permitía engrosar el endeudamiento acumulado por la casa de negocios al saldar la deuda global en un enclave determinado (Álvarez Nogal, 2005: 379-408).

En el seno de la red mercantil, hemos de señalar la relevancia del agente de letras de cambio cuya labor de mediación en la remisión/compra de mercancías y la gestión del crédito global era fundamental para el cumplimiento de los asientos (Broens, 1989: 57-60). En el caso de la compañía Cardoso-Ladrón de Guevara, Rouen se convirtió en la principal plaza de canje entre los bienes ibéricos y aquellos procedentes del Mar del Norte. Además desde allí se giraban las letras de cambio a Amberes donde se saldaba la deuda conjuntamente. Sus principales agentes en la plaza normanda fueron Antonio Rodríguez Lamego- hermano de Juan Rodríguez Lamego- que era a su vez cuñado de Enrique Núñez Saravia, y su hijo Bartolomé Febo (López Belinchón, 2001:1025; Broens, 1989: 55-57).

Entre los múltiples agentes de la compañía hemos de destacar la importancia de Duarte Núñez de Acosta. Su carrera discurrió entre Ámsterdam, Glückstadt y Hamburgo, aprovechando la condición neutral de esta última para remitir mercancías sin ninguna restricción (Israel, 1992, 11-13). Al mismo tiempo, dicho agente contaba con múltiples empleados: Juan de Liarte (Ámsterdam), Manuel Rodríguez Isidro (Hamburgo) y Miguel de Cáceres (Cádiz) -hijo de Antonio de Cáceres, este último un importante comerciante de trapos en Rouen- y colaboraba esporádicamente con Bartolomé Febo (Broens, 1989: 60-62). Duarte Núñez de Acosta, estaba emparentado con los hermanos Díaz Jorge, agentes en Ámsterdam de Bartolomé Febo, junto con los hermanos Lobo de Luna, que posiblemente guardarían algún parentesco con Duarte Jorge Núñez, cuñado de Alfonso y Diego Cardoso ${ }^{36}$.

En el seno de la compañía, un joven llamado Duarte de Acosta, sobrino de Alfonso y Diego Cardoso, comenzó su andadura como aspirante a hombre de negocios. Desde su infancia, el potencial sucesor de la casa de negocios de los Cardoso recibió una formación teórico- práctica destinada a conocer los entresijos de la empresa familiar. De esta forma, el aprendiz comenzó su andadura práctica

36. Duarte Jorge Núñez era el marido de Isabel Enríquez, hermana de Diego y Alfonso Cardoso. Testamento impreso de Duarte de Acosta. 1655. RAH, Colección Salazar y Castro E-25, fol. 174 r. 
JAVIER GÓMEZ MESAS

LOS PEREIRA, CARDOSO Y LADRÓN DE GUEVARA: TRES FAMILIAS ESPECIALIZADAS

EN EL ABASTECIMIENTO DE PERTRECHOS Y BASTIMENTOS NAVALES EN EL REINADO DE FELIPE IV

en el trato al por menor hasta alcanzar puestos vinculados a la cúpula rectora de la casa (Gómez Mesas, 2020, 339-341) ${ }^{37}$.

Gráfico 1. Provisiones de la casa de negocios de los Cardoso (1630-1642)

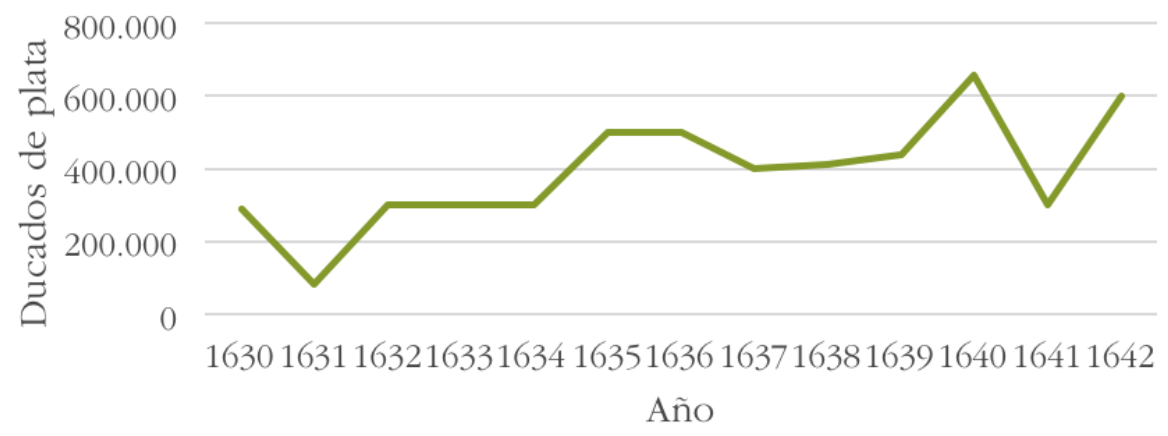

\begin{tabular}{|c|c|c|c|c|c|c|c|c|c|c|c|c|c|}
\hline Año & 1630 & 1631 & 1632 & 1633 & 1634 & 1635 & 1636 & 1637 & 1638 & 1639 & 1640 & 1641 & 1642 \\
\hline $\begin{array}{l}\text { Cifras en } \\
\text { ducados }\end{array}$ & 288.728 & 82.500 & 300.000 & 300.000 & 300.000 & 500.000 & 500.000 & 400.000 & 411.617 & 440.000 & 658.667 & 300.000 & 600.000 \\
\hline
\end{tabular}

Fuente: AGS, CCGG, leg. 120, 125, 126, 127, 128, 129, $130^{38}$.

\section{LA EVOLUCIÓN DE LA COMPAÑÍA A LA MUERTE DE ALFONSO CARDOSO DURANTE LA DÉCADA DE 1640: LA DIRECCIÓN DE MARTÍN LADRÓN DE GUEVARA}

El inicio de la década inauguró una nueva etapa en la compañía Cardoso-Ladrón de Guevara. Tras la muerte de Alfonso Cardoso en 1639, Fernando Ladrón de Guevara se convirtió en el administrador de la casa de los Cardoso bajo la estrecha vigilancia de Martín Ladrón de Guevara, el nuevo director de la compañía.

37. En cuanto a la formación teórica de los aprendices, existían múltiples impresos sobre aritmética y aspectos de contabilidad, altamente difundidos en la comunidad genovesa tales como Aritmetica Pratica per Principanti de David Varonese o La Prima parte de l'Arimmettica. Destacamos igualmente la obra de Santa Cruz, M. J., Libro de arithmetica especulatiua y pratica intitulado El dorado contador, Madrid, España, en casa de Francisco Martínez, 1643.

38. El gráfico representa los asientos concertados por la casa de negocios de los Cardoso, incluyendo las provisiones de la compañía con los Ladrón de Guevara. Parte de esta documentación fue publicada por Boyajian, 1983: 216.

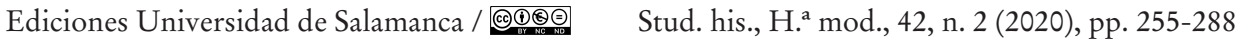


Mientras tanto, la hegemonía marítima de la monarquía hispánica tornaba a su fin. En 1638, los franceses destruían Pasajes, principal astillero de norte peninsular, y bloqueaban la costa cantábrica, hasta que las escuadras gallegas, inferiores en número, lograron recuperar la costa sufriendo un gran número de pérdidas (Goodman, 2001: 41-46). Un año más tarde, la Corona trató, en vano, de recuperar el control de Brasil. A pesar de su superioridad numérica, la flota hispánica pereció a manos de unos navíos holandeses más veloces y dinámicos ${ }^{39}$.

En el Mar del Norte, todo atisbo por restablecer el dominio hispánico se desvaneció tras la derrota de las Dunas de 1639. A pesar de la gran movilización de barcos fletados, las fuerzas imperiales sufrieron una derrota sin paliativos contra las naos de las Provincias Unidas. Los barcos holandeses, más numerosos, de mayor porte, maniobrabilidad y carga de fuego forzaron a los galeones hispánicos al enfrentamiento en línea. En consecuencia, la Armada del Mar Océano perdió la mayor parte de sus unidades, a excepción de la escuadra gallega de Andrés de Castro y un reducido contingente de barcos de corso (Fernández Duro, 1898, t. IV, c. X: 219-222). Martín Ladrón de Guevara, fue testigo directo de los hechos al servir con su propia escuadra en la flota dirigida por Oquendo (González López, 1973: 56-58).

Del mismo modo, la Armada de Flandes se encontraba en una situación límite. El número de bajeles disponibles alcanzó sus mínimas cotas dada la disminución progresiva de las presas registradas por el Almirantazgo y la paralización de la industria naval flamenca (Glete, 2000: 60-69; 180-186). El traslado de la guerra de corso al mar Cantábrico y el bloqueo de puertos como Dunkerque interrumpieron las vías de suministro a Flandes y desincentivaron el corso flamenco. Desde entonces, la vía Dover, citada anteriormente, se convirtió en la principal ruta para hacer llegar los suministros a Flandes y emprender la recomposición de las escuadras flamencas. Sin embargo la mayor parte de la industria naval se limitó a la reparación de las unidades existentes ante la falta de caudal y las dificultades en la obtención de pertrechos (Otero Lana, 2005: 111-133; Stradling, 1992: 181-183).

En el Mediterráneo, las únicas escuadras de galeras operativas y relativamente cuantiosas eran las de Nápoles, Sicilia, Génova y Cerdeña (Cipollone, 2011: 94-108; 163-170). Las galeras de la escuadra de España habían perdido la mayor parte de sus unidades o bien habían sido adecuadas a otras necesidades, además sus principales oficiales habían muerto en batalla y la marinería descendía a medida que se incrementaban las deserciones (Fernández Duro, 1898, t. IV, c. XV: 260-270).

39. Los holandeses contaban con operativos astilleros y una floreciente industria de enseres navales. Por estas fechas, los holandeses potenciaron la fabricación de naos de línea. Carta de Diego Suárez a Pedro Coloma 26/08/1640. Madrid. Archivo Museo Naval, Colección Sanz Berrutel, 940, fol. 81 r- 82 r. 
JAVIER GÓMEZ MESAS

LOS PEREIRA, CARDOSO Y LADRÓN DE GUEVARA: TRES FAMILIAS ESPECIALIZADAS

EN EL ABASTECIMIENTO DE PERTRECHOS Y BASTIMENTOS NAVALES EN EL REINADO DE FELIPE IV

Ante este desolador panorama naval, la Corona optó por garantizar la supervivencia de las armadas de la Carrera de Indias con el fin de asegurar con prontitud el caudal americano y poder negociar nuevos asientos de provisiones generales (Serrano Mangas, 1989: 18, 51; Alvarez Nogal, 1997: 21-23). El plan de rearme se fundamentó en la adquisición de bajeles extranjeros, la reactivación de la industria en los principales astilleros de la península y el aumento de la presión fiscal en Italia; empero, la falta de caudal, la pérdida de los astilleros portugueses en 1640 y la exacerbada presión fiscal frustraron los visos reformistas (Alcalá Zamora, 1975: 455-463). Entonces, la monarquía optó por fomentar el trasvase de bajeles, pertrechos y bastimentos entre las diferentes unidades navales y los presidios. Ninguna de las armadas podía concurrir de forma autónoma, ni sostenerse por sus propios medios, de este modo, la funcionalidad y la división administrativa de cada una de ellas se tornó difusa. Así, un mismo bajel podía operar en múltiples espacios adecuando su fisionomía al ámbito de operación y el servicio a realizar (Goodman, 2001: 52-59) ${ }^{40}$.

A lo largo de la década de 1640, la Corona alternó la recurrencia a los agentes privados con los intentos por centralizar la financiación y el despacho de las naos, sin embargo, la concurrencia privada terminó supliendo la mayor parte de las necesidades. En primer lugar, los oficiales reales desconocían el funcionamiento del mercado de pertrechos y bastimentos, además afrontar el coste del cambio de divisas en el extranjero era alto y resultaba más económico recurrir a un particular. En segundo lugar, los hombres de negocios contaban con extensas redes clientelares, sólidas y eficaces, operativas en todo momento, mientras la Corona no disponía ni de los contactos directos, ni la estructura mercantil para optimizar costes y allegar recursos con celeridad y con carácter extraordinario. En tercer lugar, si el despacho de las flotas corría por cuenta de la Corona, el agente real corría con la responsabilidad del buen estado de los materiales y las cantidades adquiridas, sin haber necesariamente una institución superior que auditase su acción ${ }^{41}$; mientras que si procedía el particular, la responsabilidad era privada y la Corona podía exigir el cumplimiento de los términos del contrato, instando a que las provisiones se encontrasen en buen estado ${ }^{42}$. De este modo, compañías como la de los CardosoLadrón de Guevara contaban con la estructura empresarial necesaria para garantizar el acopio de útiles navales y llevar a cabo las obras requeridas para la puesta a punto

40. Durante el valimiento de Olivares aparecieron diversas juntas con competencias en las armadas: la Junta de Armadas, la Junta de Galeras o la Junta de Guerra de Indias. Los nuevos órganos de decisión rivalizaron con los tradicionales consejos que asumían las competencias navales: Consejo de Hacienda, Consejo de Guerra y Consejo de Indias.

41. En 1642 comenzó la visita a la Casa de la Contratación emprendida por Juan de Góngora con el fin de hacer cumplir los registros e informar sobre los fraudes y prácticas de dudosa legalidad llevada a cabo por sus oficiales. Ver al respecto Heredia López, 2017: 388-410.

42. Al respecto son interesantes las reflexiones de Torres Sánchez, 2013, 159-199.

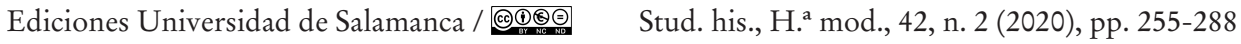


JAVIER GÓMEZ MESAS

LOS PEREIRA, CARDOSO Y LADRÓN DE GUEVARA: TRES FAMILIAS ESPECIALIZADAS

EN EL ABASTECIMIENTO DE PERTRECHOS Y BASTIMENTOS NAVALES EN EL REINADO DE FELIPE IV

de las flotas (arbolar, armar, carenar y aparejar) lo que explica su continuidad en las provisiones navales, que aumentaron a la muerte de Alfonso Cardoso.

Tras su fallecimiento, Fernando Ladrón de Guevara se convirtió en el administrador y principal representante de la casa de negocios de los Cardoso. Uno de los primeros cometidos que tuvo que desempeñar fue el de representar a María Pereira -viuda del recién fallecido- en un pleito con Beatriz Pérez -mujer del difunto Lorenzo Pereira- por el ajuste de cuentas de la antigua casa de negocios de Simón y Lorenzo Pereira. Los Pereira reclamaban el pago de unas deudas que antaño Alfonso Cardoso había mantenido con su familiaa ${ }^{43}$. Ambas partes designaron un contador y a un tercero para el ajuste del cargo y la data de la antigua casa de negocios de los Pereira. Sin embargo, ninguna de las dos partes quedaron satisfechas con el tanteo y se designó un nuevo contador: el genovés Vicenzo Squarzafigo ${ }^{44}$. Las cuentas del genovés determinaron que las deudas de los Cardoso ascendían a unos 10 cuentos y otros tantos maravedís en monedas de vellón y plata. De este modo, el alcalde don Diego de Ribera Vañez mandó ejecutar el embargo de los bienes administrados por Fernando Ladrón de Guevara hasta que se saldase el débito ${ }^{45}$.

En respuesta a la resolución de Diego de Ribera, Fernando Ladrón de Guevara interpuso una apelación, aduciendo fallos en el procedimiento empleado por Squarzafigo, acusado de ser cómplice de los Pereira. Las alegaciones fueron desestimadas y se emitió la sentencia de remate: la casa de los Cardoso debía enajenar el patrimonio necesario para saldar sus deudas ${ }^{46}$.

Mientras tanto, Martín Ladrón de Guevara se encontraba al frente de los asuntos de la compañía. Asociado a la casa de los Medinaceli, el asentista fue constante en las provisiones navales y los despachos de las flotas junto a su socio, Diego Cardoso, que cumplía una labor fundamental por dos razones: era el nexo de unión con el capital sefardita y gestionaba el cobro de las libranzas de la compañía. En 1638, la compañía apertrechó y suministró los bastimentos de doce galeones de la flota de

43. Por Doña Beatriz Pereyra, madre tutora, y curadora de sus hijos menores, y de Simón Pereyra su marido, y sus herederos, y de Lorenzo Pereyra su tío, y Consortes con Doña María Pereira, mujer de Gerónimo de Fonseca, tutora, y curadora de sus hijos, y de Alfonso Cardoso su primer marido, y don Fernando Ladrón de Guevara, administrador de la casa y negocios del dicho Alfonso Cardoso. ¿1640? BNE, PORCONES 982(18), fol.1. «3. Lo tercero que doña Beatriz en nombre de sus hijos puso diferentes capítulos de mal administrador a Alfonso Cardoso y pidió que diese cuenta de la administración de la casa y negocios de Simón y Lorenzo Pereira».

44. Una breve biografía del genovés es ofrecida por Álvarez Nogal en el Diccionario Biográfico de la RAH. Recuperado de http://dbe.rah.es/biografias/75681/vicencio-squarzafigo.

45. BNE, PORCONES 982(18), fol. 3 r- $10 \mathrm{r}$.

46. Por D. Fernando Ladrón de Guevara, Administrador de la casa y negocios de Alfonso Cardoso, y D. María Pereira mujer de Gerónimo de Fonseca, como tutora y curadora de sus hijos, y del dicho Alfonso Cardoso su primero marido. ¿1640? BNE, PORCONES/123(7), fol. $1 \mathrm{r}-16 \mathrm{r}$. 
JAVIER GÓMEZ MESAS

LOS PEREIRA, CARDOSO Y LADRÓN DE GUEVARA: TRES FAMILIAS ESPECIALIZADAS

EN EL ABASTECIMIENTO DE PERTRECHOS Y BASTIMENTOS NAVALES EN EL REINADO DE FELIPE IV

Nueva España, imponiendo como condición el pago de 90.000 ducados de plata al contado ${ }^{47}$. Ese mismo año, Martín Ladrón de Guevara y Diego Cardoso ofrecieron una escuadra de 13 galeones y 2 pataches para la Armada del Mar Océano cuya fabricación habría de durar 5 años. Como adehala de este asiento recibieron dos mercedes de hábito de la orden militar de Santiago, que pararon en Martín Ladrón de Guevara y su hijo ${ }^{48}$. Cuatro años más tarde, 1642, Martín Ladrón de Guevara, que ya residía en el Puerto de Santamaría, concertó dos asientos: uno para la Armada del Mar Océano y otro para la flota de Tierra Firme.

En lo tocante a la Armada del Mar Océano, el asentista se comprometió a remitir los pertrechos necesarios para efectuar los aprestos y carenas de los 35 bajeles propiedad de la administración durante dos años ${ }^{49}$. Para el cumplimiento del asiento, aquellos pertrechos que entrasen en la bahía de Cádiz debían ser entregados al asentista e inventariados por el veedor general, el proveedor y el mismo Martín Ladrón de Guevara ${ }^{50}$. El asiento fue todo un éxito y en los mismos términos fue prorrogado por dos años más (Serrano Mangas, 1989: 80).

TABla 2. Asiento de Martín Ladrón de Guevara y Diego Cardoso para la Armada del Mar Océano (1642-1643)

\begin{tabular}{|c|c|c|c|c|}
\hline Asiento & Consignaciones & Adehalas & Facultades & Deudas a cobrar \\
\hline $\begin{array}{l}\text { Provisión de bastimentos. } \\
\text { Realización de carenas, } \\
\text { aprestos y mantenimiento } \\
\text { de } 35 \text { bajeles. Total: } 19.063 \\
\text { toneladas. } \\
\text { Interés de dilación: } 7 \% \text {. } \\
\text { Conducción: } 3 \% \text {. }\end{array}$ & $\begin{array}{l}25 \text { pagas a } 9 \text { reales/tonelada. } 1 / 2 \\
\text { en vellón+ } 1 / 2 \text { en plata: } 388.885 \\
\text { ducados en renta de salinas del } \\
\text { Reino con posibilidad de elección } \\
\text { del partido por el asentista. }\end{array}$ & \begin{tabular}{|l|}
2 patentes en \\
blanco (capitán \\
y almirante). \\
\\
\end{tabular} & $\begin{array}{l}\text { Licencia para emplear } \\
4 \text { barcos luengos y } 4 \\
\text { gavanas para importar } \\
\text { géneros foráneos libre } \\
\text { de embargos. } \\
\text { Licencia de saca de } \\
100.000 \text { ducados de } \\
\text { plata por cada año de } \\
\text { duración del contrato. }\end{array}$ & $\begin{array}{l}6.636 \text { ducados de plata y } \\
1.161 \text { ducados de vellón por } \\
\text { la provisión de pertrechos y } \\
\text { bastimentos a la capitana y } \\
\text { almiranta de Nueva España } \\
\text { de } 1640 \text {. } \\
\text { Deudas de las provisiones de } \\
\text { la Armada del Mar Océano de } \\
1641: 1 / 2 \text { consignado en flota de } \\
1642+1 / 2 \text { en flota de } 1643 \text {. }\end{array}$ \\
\hline
\end{tabular}

Fuente: AGMM, Depósito Histórico, leg. 43, fol. 29 r- 34 v.

47. En las consignaciones, 60.000 ducados de los 90.000 ducados que debía percibir al contado se harían efectivos con el incremento del $1 \%$ de toneladas. El resto de las consignaciones se situaban en el caudal de la flota de Nueva España de ese año. Carta de Francisco Díaz Contreras a los presidentes y jueces oficiales de la Casa de la Contratación. 18/01/1638. Madrid. AGI, Indiferente, 2500, leg. 17, fol. 254 r- $258 \mathrm{v}$.

48. AHN, OM, Expedientillos_Santiago, Exp. 2556.

49. Asiento de Martín Ladrón de Guevara para el apresto y carena de 35 bajeles y la provisión de pertrechos y bastimentos para la escuadra San Joseph que sirve en la dicha armada. 1642. Madrid. AGMM, Depósito Histórico, leg. 43, fol. 29 r- 34 v.

50. Ibidem, Cláusula 2 y 3.

Ediciones Universidad de Salamanca / 요 Stud. his., H. ${ }^{a}$ mod., 42, n. 2 (2020), pp. 255-288 
En cuanto a las escuadras indianas, Martín Ladrón de Guevara se encargó de surtir de pertrechos a los siete galeones de la administración destinados a Tierra Firme en 1642. Además, el galeón de su propiedad, el Nuestra Señora de la Concepción, serviría en el viaje de ida como mercante a cuenta del Consulado y en el viaje de vuelta como galeón de la plata ${ }^{51}$. Los pertrechos debían remitirse en Cádiz al tenedor de bastimentos bajo la supervisión del contador y el veedor general en el tiempo establecido. En caso de que los envíos se retrasasen, el asentista correría con el coste y riesgo de las provisiones ${ }^{52}$. Si se necesitaban más materiales de los estimados, Martín Ladrón de Guevara debía proporcionar los géneros al mismo precio y bajo las mismas condiciones ${ }^{53}$. En cuanto a las consignaciones, las libranzas al contado eran requisito imprescindible para proceder a la compra de los géneros. Las libranzas en plata podían ser entregadas tanto a Martín Ladrón como a su socio Diego Cardoso; además, si la plata venía en barras podía ser sacada del reino para proceder a su acuñación en otros enclaves ${ }^{54}$.

Tabla 3. Asiento de Martín Ladrón de Guevara y Diego Cardoso para la flota de Tierra Firme de 1643

\begin{tabular}{|l|l|l|}
\hline \multicolumn{1}{|c|}{ Asiento } & \multicolumn{1}{|c|}{ Consignaciones } & \multicolumn{1}{c|}{ Deudas a cobrar } \\
\hline Abasto de pertrechos y bastimentos & Total por abasto de pertrechos: & Flota de Tierra Firme 1640: () 2.810 \\
a 7 bajeles de la administración. & 112.756 ducados de plata en géneros: & ducados de plata del sueldo de la \\
Carena y apresto de su galeón tanto & () 23.012 ducados de plata al contado & nao Nuestra Señora de la Esperanza \\
en España como en Indias & $(20,40 \%)$. & por su servicio como galeón de \\
& () 89.744 ducados en plata, del caudal & plata al mando de Gómez de \\
& de la flota de Tierra Firme (79,60\%) & Sandoval ${ }^{1 .}$ \\
& Total por flete de navío: 2.833 & () 495 ducados de plata por 111 \\
& ducados de plata de la flota de Tierra & quintales de arroz para la Armada \\
& Firme. & de Tierra Firme de 1640². \\
\hline
\end{tabular}

Fuente: AGI, Indiferente, leg. 2501, lib. 19, fol. 125 v-133 r, 175 r-177 v.

El asiento sufrió distintas modificaciones. Ante el escaso caudal de la Avería y la falta de rentas disponibles para dar cabida a las consignaciones al contado. Por ende, Martín Ladrón de Guevara paralizó sus provisiones hasta que no se le hiciesen

51. Asiento de Martín Ladrón de Guevara para la provisión de pertrechos para la carena de 8 bajeles de la flota de Tierra Firme de 1642. 10/08/1642. Madrid. AGI, Indiferente, leg. 2501, lib. 19, fol. $125 \mathrm{v}-133 \mathrm{r}$.

52. Ibidem, Cláusula 3.

53. Ibidem, Cláusula 7.

54. Ibidem, Cláusulas 12 y 13. 
JAVIER GÓMEZ MESAS

LOS PEREIRA, CARDOSO Y LADRÓN DE GUEVARA: TRES FAMILIAS ESPECIALIZADAS

EN EL ABASTECIMIENTO DE PERTRECHOS Y BASTIMENTOS NAVALES EN EL REINADO DE FELIPE IV

efectivas al no contar con liquidez. Dada la premura en la partida de las flotas, el rey instó al presidente y los jueces oficiales de la Casa de la Contratación a tomar prestado o por asientos con particulares el dinero necesario para concluir los aprestos de los 7 bajeles destinados a Tierra Firme ${ }^{55}$, comprometiéndose a consignar lo adelantado en el caudal procedente de la flota de Tierra Firme de $1643^{56}$.

Antes de su partida, la flota de Tierra Firme se vio acrecentada en cuatro bajeles procedentes de la Armada del Mar Océano, 3 galeones y 1 patache incautado, cuya carena y apresto corrió a cuenta de Martín Ladrón de Guevara. El coste total de las reparaciones y obras de puesta a punto ascendió a 40.000 ducados de plata ${ }^{57}$. Para atender los nuevos requerimientos, Martín Ladrón de Guevara percibió una cantidad al contado procedente de nuevos asientos concertados con comerciantes y 50.000 escudos enviados por la Real Hacienda a la Casa de la Contratación ${ }^{58}$. El resto se abonaría a la llegada de la flota de Tierra Firme de $1643^{59}$. Sin embargo, la carena de las cuatro embarcaciones de refuerzo fue defectuosa y los oficiales reales debieron acometer desembolsos extraordinarios en América (Serrano Mangas, 1990: 82-84) ${ }^{60}$.

Hasta al menos 1648, la mayor parte de las provisiones generales fueron sufragadas por el capital luso. Con la marcha de Felipe IV y Olivares al frente catalán, Isabel de Borbón y el conde de Castrillo se convirtieron en los principales encargados de ajustar los asientos de provisiones generales de 1643 (Franganillo, 2001). En enero de 1643, el rey depuso a Olivares y don Luis de Haro se convirtió en su principal persona de confianza: el periodo de influencia de los judeoconversos portugueses había «teóricamente» concluido. A pesar de la Restauraçao y la caída en desgracia del valido, la mayor parte de las provisiones de dinero de la monarquía hispánica fueron sufragadas por el crédito portugués. Junto a ellos, reaparecieron linajes de genoveses que tras 1627 habían continuado su actividad crediticia con la Corona, principalmente a través de otros agentes (Álvarez Nogal, 2010, 1095-1124). Entre ellos podemos destacar, los Centurione (Sanz Ayan, 2015), los Pallavicino (Álvarez Nogal, 1997: 65-70) o los Balbi (Grendi, 1997).

55. Despacho Real al presidente y jueces oficiales de la Casa de la Contratación. 11/12/1642. Madrid. AGI, Indiferente, leg. 2501, lib. 19, fol. 151 v- 152 v.

56. Carta de Gabriel de Ocaña y Alarcón al presidente y jueces oficiales de la Casa de Contratación. Madrid. 11/12/1642. AGI, Indiferente, leg. 2501, lib. 19, fol. 173 v-175 r.

57. Carta de Gabriel de Ocaña y Alarcón al general Francisco Díaz Pimienta. 17/04/1643. Madrid. AGI, Indiferente, leg. 2501, lib. 19, fol. 219 v-220 v.

58. Carta de Gabriel de Ocaña y Alarcón al general Francisco Díaz Pimienta. 07/05/1643. Madrid. AGI, Indiferente, leg. 2501, lib. 19, fol. 231 r-232 r.

59. Cédula Real al general Francisco Díaz Pimienta. 09/12/164. Madrid. AGI, Indiferente, leg. 2501, lib. 19, fol. 277 r-279 v

60. El coste de reparación y de adquisición de pertrechos en América ascendió a 30.312 ducados de plata.

Ediciones Universidad de Salamanca / @®@@ Stud. his., H. ${ }^{a}$ mod., 42, n. 2 (2020), pp. 255-288 
JAVIER GÓMEZ MESAS

LOS PEREIRA, CARDOSO Y LADRÓN DE GUEVARA: TRES FAMILIAS ESPECIALIZADAS

EN EL ABASTECIMIENTO DE PERTRECHOS Y BASTIMENTOS NAVALES EN EL REINADO DE FELIPE IV

Entre 1643-1645, la compañía encabezada por Martín Ladrón de Guevara, no cesó en las provisiones navales e incluso atendió nuevos negocios ${ }^{61}$. En 1643, suministró 4.000 raciones de bastimentos y cubrió las carenas y aprestos de tres bajeles de la Armada del Mar Océano ${ }^{62}$.

Tabla 4. Asiento de Martín Ladrón de Guevara para la Armada del Mar Océano (1643)

\begin{tabular}{|l|l|}
\hline Asiento & Consignaciones \\
\hline 4.000 raciones de bastimentos. & Valor global del asiento: 52.300 ducados: \\
Carenas y apresto de tres bajeles de la Armada & () 23.466 ducados en plata (44'86\%). \\
del Mar Océano. & () 28.834 ducados en vellón (55'14\%). \\
& Consignado en el caudal de la Avería \\
& 26.150 ducados: \\
& () 11.733 ducados en vellón (44'86\%). \\
& () 14.416 ducados en plata (55'14\%). \\
\hline
\end{tabular}

Fuente: AGI, Indiferente, leg. 2501, lib. 20, fol. 54 r-55 v.

En enero de 1644, Martín Ladrón de Guevara concertó un nuevo asiento por el que se comprometía a realizar todas las obras de carpintería, carena, arboladura y puesta a punto de los doce galeones y dos pataches de la flota de Tierra Firme de 1644. Asimismo, el asentista proporcionaría todos los géneros necesarios para la realización de dichas obras ${ }^{63}$.

Con el fin de evitar nuevas irregularidades en las obras realizadas por Martín Ladrón de Guevara, la Junta de Guerra de Indias nombró a dos personas encargadas de verificar la correcta realización de las obras. Por los defectuosos aprestos realizados por el asentista en la flota de Tierra Firme de 1643, Juan de Góngora se convirtió en el juez privativo en primera instancia de la causa abierta contra Martín Ladrón de Guevara ${ }^{64}$. A pesar de tener causas pendientes en su contra, Martín Ladrón de

61. Martín Ladrón de Guevara suministró 500 quintales de pólvora a Badajoz por medio de un asiento firmado el 24/09/1643. Las consignaciones de este asiento, 13.600 ducados de plata, se situaron en el caudal de la flota de Tierra Firme de 1643. Cédula Real a Francisco Diaz Pimienta. 29/10/1643. Madrid. AGI, Indiferente, leg. 2501, lib. 19, fol. 276 v-277 v

62. Cédula Real para que la Casa de la Contratación entregue a Martín Ladrón de Guevara 22.287 escudos de lo procedido de la averías de los últimos galeones de lo que ha de haber por la Armada del Mar Océano. 23/05/1644. Madrid. AGI, Indiferente, 2501, lib. 20, fol. 54 r- 55 r.

63. Asiento de Martín Ladrón de Guevara para el apresto de los galeones de la flota de Tierra Firme de 1644. 30/01/1644. Madrid. AGI, Indiferente, leg. 2501, lib.20, fol. 13 r-18 v.

64. Aprobación del asiento de Martín Ladrón de Guevara. 04/04/1644. Zaragoza. AGI, Indiferente, leg. 2501, lib. 20, fol. $20 \mathrm{v}-23 \mathrm{v}$.

Ediciones Universidad de Salamanca / @®@@ Stud. his., H. ${ }^{a}$ mod., 42, n. 2 (2020), pp. 255-288 
JAVIER GÓMEZ MESAS

LOS PEREIRA, CARDOSO Y LADRÓN DE GUEVARA: TRES FAMILIAS ESPECIALIZADAS

EN EL ABASTECIMIENTO DE PERTRECHOS Y BASTIMENTOS NAVALES EN EL REINADO DE FELIPE IV

Guevara, se comprometió a aprestar y carenar seis urcas para la Armada del Mar Océano. El valor del asiento ascendió a 100.000 ducados, 40.000 ducados al contado en plata (40\%) y 60.000 ducados de plata en la flota de Tierra Firme de 1644 (60\%) (Serrano Mangas, 1989: 85).

Tabla 5. Asiento de Martín Ladrón de Guevara para la flota de Tierra Firme (1644)

\begin{tabular}{|l|l|l|}
\hline Asiento & Consignaciones & Deudas a cobrar \\
\hline Provisión de pertrechos y & Total por las obras: & Pago de lo adeudado en Nueva \\
enseres necesarios para la & 215.000 ducados de plata & España por el asiento para el \\
puesta a punto de la flota. & doble: & apresto de la capitana, almiranta \\
Obras de carpintería, carena, & () 100.000 al contado & y siete navíos auxiliares \\
arboladura y aparejar los doce & de la Avería del año & de la frustrada Armada de \\
galeones y dos pataches de la & precedente. & Barlovento (Torres Ramírez, \\
flota. & () 115.000 del caudal & 1981: 47-51). \\
& indiano procedente en & \\
& esa flota. & \\
\hline
\end{tabular}

Fuente: AGI, Indiferente, leg. 2501, lib. 20, fol. 13 r- 23 v.

En su último año de vida, 1645, Martín Ladrón de Guevara realizó la carena de 14 navíos y suministró 1.500 .000 raciones a la Armada del Mar Océano. Como condición de este asiento, Martín exigió la condonación de las libranzas y deudas que la Real Hacienda mantenía con la compañía por anteriores asientos: 157.541 ducados en plata que debían remitirse al contado en Cádiz y un juro pendiente de 2.000 ducados de renta anual como adehala de un asiento de $1642^{65}$.

En diciembre de 1645, Martín Ladrón Guevara agonizaba en su lecho mientras Fernando Ladrón de Guevara, por aquel entonces contador en la Contaduría Mayor de Cuentas, suscribió un asiento en nombre de su padre. Fernando Ladrón de Guevara se comprometía a proporcionar aquellos pertrechos necesarios para el despacho de la flota de Tierra Firme y la capitana y almiranta de la flota de Nueva España de $1646^{66}$. Para la realización del asiento, Fernando Ladrón de Guevara exigía el cese de las averiguaciones llevadas a cabo por Francisco de Robles por las malas carenas realizadas en la flota de Tierra Firme de 1643 y propuso a un

65. El juro estaba exento del pago de la media anata. Cuentas de Martín Ladrón de Guevara el asiento de la Armada del Mar Océano de 1645. 13/01/1645. Madrid. AHN, Hacienda, 7890, fol. $13 \mathrm{r}-13 \mathrm{v}$.

66. Aprobación del asiento de Martín y Fernando Ladrón de Guevara para el apresto de la Armada que ha de ir a Tierra Firme y la capitana y almiranta de Nueva España. 25/12/1645. Sevilla. AGI, Indiferente, leg. 2501, lib. 20, fol. 326 v-336 r.

Ediciones Universidad de Salamanca / @®@@ Stud. his., H. ${ }^{a}$ mod., 42, n. 2 (2020), pp. 255-288 
JAVIER GÓMEZ MESAS

LOS PEREIRA, CARDOSO Y LADRÓN DE GUEVARA: TRES FAMILIAS ESPECIALIZADAS

EN EL ABASTECIMIENTO DE PERTRECHOS Y BASTIMENTOS NAVALES EN EL REINADO DE FELIPE IV

representante suyo y un contador de la Real Hacienda para evaluar los posibles perjuicios cometidos en su contra ${ }^{67}$.

Tabla 6. Asiento de Martín Ladrón de Guevara

para la flota de Tierra Firme y capitana y almiranta de Nueva España de 1646

\begin{tabular}{|c|c|c|c|}
\hline Asiento & Consignaciones & Facultades & Deudas a cobrar \\
\hline $\begin{array}{l}\text { Provisión de géneros } \\
\text { para el apresto de la } \\
\text { capitana y almiranta } \\
\text { de Nueva España y la } \\
\text { flota de Tierra Firme. }\end{array}$ & $\begin{array}{l}\text { Total de las provisiones: } \\
129.888 \text { ducados de } \\
\text { plata: } \\
\text { () } 51.955 \text { ducados de } \\
\text { plata al contado }{ }^{4} \text {. } \\
\text { () } 77.933 \text { ducados de la } \\
\text { plata de Nueva España. }\end{array}$ & $\begin{array}{l}\text { Licencias de saca de } 70.000 \\
\text { ducados de plata en reales } \\
\text { o barra. } \\
\text { Licencia para embarcar } \\
\text { mercancías en los puertos } \\
\text { cantábricos: } 1 / 2 \text { en bajeles } \\
\text { enemigos; } 1 / 2 \text { en bajeles } \\
\text { aliados, libre de embargos. }\end{array}$ & $\begin{array}{l}\text { Libranza de } 120.000 \\
\text { ducados de plata } \\
\text { pendiente por los } \\
\text { aprestos de la flota } \\
\text { de Tierra Firme de } \\
1644^{5} \text {. }\end{array}$ \\
\hline
\end{tabular}

Fuente: AGI, Indiferente, leg. 2501, lib. 20, fol. 326 v-336 r.

El asiento sufrió modificaciones. En mayo de 1646, el tenedor de bastimentos embargó géneros por valor de 15.000 escudos $^{68}$ y tras la muerte de Martín Ladrón de Guevara, la Corona dio órdenes a Fernando Ladrón de Guevara para encaminar sus provisiones a la Armada de Barlovento en lugar de la de Tierra Firme ${ }^{69}$. Fue entonces cuando el capitán Francisco de Vergara, vecino la collación de San Isidro y apoderado de Fernando Ladrón de Guevara, suscribió un nuevo asiento destinado a cubrir el abasto de pertrechos de la Armada de Barlovento ${ }^{70}$.

Gracias al concierto continuado de asientos, la compañía garantizó el cobro de las deudas que la Real Hacienda tenía pendientes, así como el sobreseimiento de las causas abiertas por fraudes o defectuosa realización de obras. Dada la vitalidad de sus provisiones y las múltiples operaciones en liza, buena parte de sus consignaciones se situaron en la plata proveniente en cada una de las flotas que la compañía había provisto, apertrechado o mantenido. Por otro lado, las consignaciones al

67. Ibidem, Cláusula 2,3.

68. Carta de don Gabriel de Ocaña y Alarcón a Gerónimo de la Torre. 27/05/1646. Madrid. AGI, Indiferente, leg. 2502, lib.21, fol.17 r.

69. Carta de Gabriel de Ocaña a Juan de Góngora. 22/04/1646. Madrid. AGI, Indiferente, leg. 2502, lib. 21, fol. 8 r.

70. Aprobación del asiento que se ha tomado con Fernando Ladrón de Guevara sobre la provisión de géneros y pertrechos para el apresto de la Armada de Barlovento y la capitana y almiranta de Nueva España. 26/07/1646. Madrid. AGI, Indiferente, leg. 2502, lib. 21, fol. $92 \mathrm{r}-101 \mathrm{r}$.

Ediciones Universidad de Salamanca / @®@@ Stud. his., H. ${ }^{a}$ mod., 42, n. 2 (2020), pp. 255-288 
JAVIER GÓMEZ MESAS

LOS PEREIRA, CARDOSO Y LADRÓN DE GUEVARA: TRES FAMILIAS ESPECIALIZADAS

EN EL ABASTECIMIENTO DE PERTRECHOS Y BASTIMENTOS NAVALES EN EL REINADO DE FELIPE IV

contado ofrecieron a la compañía la liquidez necesaria para emprender la compra de materiales en el exterior y acopiar productos perecederos como los bastimentos.

Tabla 7. Asiento del capitán Francisco de Vergara

para la Armada de Barlovento y capitana y almiranta de Nueva España (1646)

\begin{tabular}{|l|l|l|}
\hline Asiento & Consignaciones & Deudas a cobrar \\
\hline $\begin{array}{l}\text { Provisión de materiales } \\
\text { necesarios para el apresto de } \\
\text { la Armada de Barlovento y la } \\
\text { capitana y almiranta de Nueva } \\
\text { España. }\end{array}$ & $\begin{array}{l}\text { Total de las provisiones: } 70.000 \\
\text { ducados de plata: }\end{array}$ & $\begin{array}{l}120.000 \text { ducados } \\
\text { pendientes por las } \\
\text { carenas de la flota de } \\
\text { Tierra Firme de } 1644^{6} .\end{array}$ \\
& $\begin{array}{l}\text { contado. } 42.000 \text { ducados de plata al } \\
\text { capitana y almiranta de Nueva la } \\
\text { España. }\end{array}$ & \\
\hline
\end{tabular}

Fuente: AGI, Indiferente, leg. 2502, lib. 21, fol. 92 r-101 r.

A la muerte de Martín Ladrón de Guevara, Fernando Ladrón de Guevara tomo la dirección de la compañía continuando con las inversiones previas. Así, prorrogó la administración de las salinas del reino por cinco años (1643-1648) $)^{71}$. Al poco tiempo de hacerse cargo de la compañía, Fernando Ladrón de Guevara hacía un balance de sus negocios y consideraba haber incrementado los beneficios legados por su padre, tal y como expresaba en su testamento ${ }^{72}$ :

[...] yo he trabajado con mi industria y viajes que he hecho a las Indias y otras partes y he aumentado la herencia [hace referencia a la herencia legada por su padre Martín Ladrón de Guevara] en mucha cantidad [...]

Por otra parte, Duarte de Acosta se encargó de los aprestos y la provisión de bastimentos a las distintas armadas. Mientras los abastos a la escuadra de galeras de España corrieron por cuenta de Ventura Donis, uno de los principales financieros de la década de 1650, que estuvo al frente de la factoría de la escuadra de galeras de España, al tiempo que controlaba la intendencia de las salinas del norte peninsular (Sanz Ayán, 1998: 33-57; Gómez Mesas, 2020, 342-345). El fin de la prohibición mercantil con las Provincias Unidas devolvió la comercialización de los pertrechos a los holandeses: había concluido la labor de mediación que hasta entonces había

71. Cuenta tocante a la administración general de las salinas del reino. 1644. Madrid. AHN, Hacienda, lib. 7889, fol. 50 r.

72. Testamento de Fernando Ladrón de Guevara. 02/06 /1656. Madrid. AHPNM, leg. 7844, fol. 704 r-717 r.

Ediciones Universidad de Salamanca / @®@@ Stud. his., H. ${ }^{a}$ mod., 42, n. 2 (2020), pp. 255-288 
JAVIER GÓMEZ MESAS

LOS PEREIRA, CARDOSO Y LADRÓN DE GUEVARA: TRES FAMILIAS ESPECIALIZADAS

EN EL ABASTECIMIENTO DE PERTRECHOS Y BASTIMENTOS NAVALES EN EL REINADO DE FELIPE IV

desempeñado el crédito portugués (Crespo Solana, 2009: 3-29; Sanz Ayán, 1992, 942-945).

\section{CONCLUSIONES}

A partir del estudio de estas tres familias hemos explicado el proceso por el que distintas casas de negocios portuguesas, vinculadas con cristianos viejos, se asentaron en Castilla, consolidaron sus negocios primigenios y diversificaron su estrategia mercantil, haciendo del abasto a las unidades navales de la monarquía hispánica su inversión principal.

Con el fin de monopolizar las provisiones de pertrechos y bastimentos navales, los Cardoso formaron una compañía con los Ladrón de Guevara, vinculados al área navarra y el mar Cantábrico, que perduró durante las décadas de 1630 y 1640 a pesar de la muerte de sus principales dirigentes. Gracias a su reseñable capacidad crediticia y la vitalidad de sus provisiones, la compañía gozó de cierta cobertura legal en el cometido de sus intercambios en el eje atlántico y alejó las acciones procesales del Santo Oficio.

En la planificación mercantil de la compañía, el éxito del negocio estrella pendió de múltiples micro-inversiones realizadas de forma simultánea en diferentes escalas territoriales. Gracias a una tupida red de agentes, empleados y corresponsales distribuidos en diversos enclaves, los Cardoso-Ladrón de Guevara gestionaron el crédito de forma eficiente y obtuvieron los enseres navales necesarios para realizar los asientos de provisiones, a pesar de las restricciones comerciales con las Provincias Unidas y Francia. En virtud de los repetidos servicios de la compañía en la puesta a punto de las flotas, sus consignaciones se situaron en efectos relativamente seguros como las salinas o las remesas americanas, las deudas pendientes fueron libradas por la Real Hacienda (sino totalmente al menos de forma parcial) y las causas abiertas por fraudes o acciones legales fueron sobreseídas. Asimismo percibieron toda una serie de prebendas sociales de incuantificable valor que atestiguaban la posición social de sus integrantes gracias al poder del dinero.

A pesar de los visos por centralizar el despacho de las distintas unidades navales; bien a través de un sistema mixto como las factorías en las que participaron varios de los hombres de negocios analizados; o mediante la administración real directa, la Corona recurrió, mayoritariamente, a agentes privados. El hecho decisivo fue la falta de caudal de la Real Hacienda para atender tan laboriosa empresa. En su lugar, cedió tal menester a compañías con redes mercantiles amplias y flexibles al complejo contexto político y socio-económico. A pesar de las restricciones mercantiles y las dilaciones en el cobro de las consignaciones, la compañía analizada suministró de forma continua enseres navales a un precio competitivo. Ello pone de relieve el control que esta compañía tenía sobre su propia cadena de distribución y transporte y la

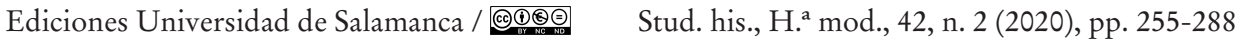


JAVIER GÓMEZ MESAS

LOS PEREIRA, CARDOSO Y LADRÓN DE GUEVARA: TRES FAMILIAS ESPECIALIZADAS

EN EL ABASTECIMIENTO DE PERTRECHOS Y BASTIMENTOS NAVALES EN EL REINADO DE FELIPE IV

sincronización con los empleados de la puesta a punto de las flotas de los pertrechos y bastimentos. Por consiguiente los hombres de negocios analizados se convirtieron en agentes sociales imprescindibles para la Corona, a pesar de la dudosa limpieza de sangre de alguno de sus integrantes.

\section{BIBLIOGRAFÍA}

Aguado de los Reyes, J. (2005). El apogeo de los judíos portugueses en la Sevilla Americanista. Cuadernos de Estudios Sefarditas, 5, 133-157.

Alcalá Zamora y Queipo de Llano, J. (1975). España, Flandes y el Mar Del Norte (16181639). Barcelona: Planeta.

Alloza Aparicio, Á. y Zofío Llorente, J. C. (2013). La trepidante carrera de sir Benjamin Wright. Comerciante, factor y asentista de Felipe IV. Hispania. Revista Española de Historia, 73(245), 673-702.

Alloza Aparicio, Á. y Zofío Llorente, J. C. (2006). Europa en el mercado español. Mercaderes, represalias y contrabando en el siglo XVII. Salamanca: Junta de Castilla y León.

Álvarez Nogal, C. (1997). Los banqueros de Felipe IV y los metales preciosos americanos (1621-1665). Madrid: Banco de España.

Álvarez Nogal, C. (1999). El factor general del rey y las finanzas de la Monarquía Hispánica. Revista de Historia Económica, 17(3), 507-539.

Álvarez Nogal, C. (2005). El transporte de moneda en la España del siglo XVII: mecanismos y costes. Revista de Historia Económica, 23(1), pp. 379-408.

Álvarez Nogal, C. (2010). El poder de los banqueros genoveses en la corte de Felipe IV. En J. Martínez Millán y M. Rivero Rodríguez (eds.), Centros de poder italianos en la Monarquía Hispánica (siglos XV-XVIII) (vol. 2, pp. 1095-1124). Madrid: Polifemo.

Álvarez Nogal, C. (2012). La factorie générale du roi dans les finances de la monarchie espagnole au milieu du XVII siècle. En A. Dubet y J. P. Luis (eds.), Les financiers et la construction de l'État. France, Espagne (XVII-XIX siècle) (pp. 33-50). Rennes: Presses Universitaires de Rennes.

Andújar Castillo, F. (2018). Hombres de negocios y cargos públicos: el acceso venal a los cargos del Consejo de Hacienda en el siglo XVII. En R. Torres Sánchez (ed.), Studium, Magisterium et Amicitia. Homenaje al profesor Agustín González Enciso (pp. 169-176). Pamplona: Eunate.

Berajano Pellicer, C. y García Bernal, J. (2018). Las fiestas patronales de la cofradía de San Antonio de los Portugueses: música y devoción. En F. Quiles, M. Fernández Chaves, M. y A. Fialho Conde (eds.), La Sevilla lusa: la presencia portuguesa en el reino de Sevilla durante el Barroco (pp. 380-400). Sevilla: Universo Barroco Iberoamericano.

Bertrand, G. (2005). Les négociants étrangers à Rouen à l'époque de Richelieu et de Mazarin (1625-1660). Annales de Normandie, 55(3), 247-266.

Boyajian, J. C. (1983). Portuguese Bankers at the court of Spain 1626-1650. New Jersey: University of New Jersey.

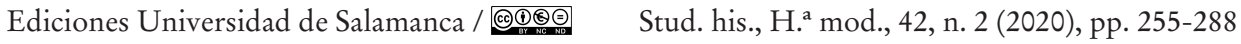


JAVIER GÓMEZ MESAS

LOS PEREIRA, CARDOSO Y LADRÓN DE GUEVARA: TRES FAMILIAS ESPECIALIZADAS EN EL ABASTECIMIENTO DE PERTRECHOS Y BASTIMENTOS NAVALES EN EL REINADO DE FELIPE IV

Broens, N. (1989). Monarquía y capital mercantil: Felipe IV y las redes comerciales portuguesas. Madrid: Universidad Autónoma de Madrid.

Carlos Morales, C.J. (2019). El encuentro entre Olivares y los banqueros conversos portugueses (1625-1628). Libros de la Corte, 19, 151-177.

Carrasco Vázquez, J. A. (2004). La minoría judeoconversa en la época del Conde Duque de Olivares. Auge y ocaso de Juan Núñez Saravia (1585-1639) (Tesis doctoral). Universidad de Alcalá de Henares.

Cipollone, V. (2011). La politica navale della Spagna nel fronte mediterraneo (1635-1678) (Tesis doctoral). Universitá di Cagliari.

Crespo Solana, A. (2009). Mercaderes atlánticos. Redes del comercio flamenco y holandés entre Europa y el Caribe. Córdoba: Universidad de Córdoba.

Díaz Blanco, J. M. (2009). El comercio de el Puerto de Santa María en la década de 1630 ¿una coyuntura crítica?. Revista de Historia de El Puerto, 43, 69-86.

Díaz Blanco, J. M. (2012). Asi trocaste tu gloria. Guerra y comercio colonial en la España del siglo XVII. Madrid: Marcial Pons.

Domínguez Ortiz, A. (1960). Politica y Hacienda de Felipe IV. Madrid: Editorial de Derecho Financiero.

Elliott, J. H. (2012). El Conde Duque de Olivares. Barcelona: Crítica.

Ebben, M. (1993). Un triángulo imposible: la Corona española, el Santo Oficio y los banqueros portugueses, 1627-1655, 53 (184), 541-556

Fernández Duro, C. (1898). Historia de la Armada Española desde la unión de los reinos de Castilla y Aragón. Vol. IV. Madrid: Impresores de la Real Casa.

Franganillo Álvarez, A. (2001). La reina Isabel de Borbón: las redes de poder en torno a su casa (1621-1644) (Tesis doctoral). Universidad Complutense de Madrid.

García Montón, A. (2015). Corona, hombres de negocios y jueces conservadores. Un acercamiento en escala transatlántica (s. XVII). Revista de Historia Jerónimo Zurita, 90, 75-112.

Giménez Carrillo, D. M. (2015). Nobleza y riqueza. Comerciantes en las Órdenes Militares castellanas. En J. J. Iglesias Rodríguez, R. M. Pérez García y M. F. Fernández Chaves (eds.), Comercio y cultura en la Edad Moderna. Actas de la XIII Reunión Científica de la FEHM (pp. 673-683). Sevilla: Editorial Universidad de Sevilla.

Glete, J. (2000). Warfare at Sea, 1500-1650: Maritime conflict and the transformation of Europe. New York: Routledge.

Gómez Mesas, J. (2020). Duarte de Acosta «el judío confeso mas pudesco que ay en la Corte ni en Castilla» (1622-1655). En J. J. Iglesias Rodríguez y I.M. Muñoz (eds.), Hacer historia moderna. Lineas actuales y futuras de investigación (pp. 332-345). Sevilla: Editorial Universidad de Sevilla, 332-345.

González López, E. (1973). El águila caída: Galicia en los reinados de Felipe IV y Carlos II. Santiago de Compostela: Galaxia.

Goodman, D. (2001). El poderío naval español. Historia de la armada española del siglo XVII. Barcelona: Ediciones Península.

Grendi, E. (1997). I Balbi. Una famiglia genovese fra Spagna e Genova. Torino: Einaudi.

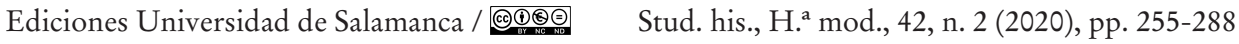


JAVIER GÓMEZ MESAS

LOS PEREIRA, CARDOSO Y LADRÓN DE GUEVARA: TRES FAMILIAS ESPECIALIZADAS EN EL ABASTECIMIENTO DE PERTRECHOS Y BASTIMENTOS NAVALES EN EL REINADO DE FELIPE IV

Heredia López, A. J. (2017). La visita a la Casa de la Contratación y Consulado de Sevilla en 1642: orígenes y motivaciones de un instrumento de control. Tiempos Modernos, 35, 388-410.

Herrero Sánchez, M. (1993). La explotación de las salinas de Punta de Araya: un factor conflictivo en el proceso de acercamiento hispano-neerlandés (1648-1677). Cuadernos de Historia Moderna, 14, 173-196.

Herrero Sánchez, M. (2005). La quiebra del sistema hispano-genovés (1627-1700). Hispania. Revista española de Historia, 65(219), 115-151.

Hofmeester, K. (2018). Economic institutions and shifting labour relations in the Indian, Brazilian, and South African diamond mines. En K. Hofmeester (ed.), Colonialism, institutional change and shifts in global labour relations (pp. 67-107). Ámsterdam: Amsterdam University Press.

Israel, J. (1992). La judería europea en la era del mercantilismo, 1550-1750. Madrid: Cátedra.

López Belinchón, B.J. (2001). «Sacar la sustancia al reino». Comercio, contrabando y conversos portugueses, 1621-1640. Hispania. Revista Española de Historia, 61(209), 1017-1050.

López-Salazar Codes, A. I. (2010). Inquisición portuguesa y Monarquía Hispánica en tiempos del Perdón General de 1605. Lisboa: Colibri.

Maffi, D. (2013). En defensa del Imperio: los ejércitos de Felipe IV y la guerra por la begemonía europea (1635-1659). Madrid: Actas.

Marchena Giménez, J. M. (2010). La vida y los hombres de las galeras de España (siglos XVI-XVII) (Tesis doctoral). Universidad Complutense de Madrid.

Marcos Martín, A. (2001). España y Flandes (1618-1648): la financiación de la guerra. En J. Alcalá-Zamora y Queipo de Llano y E. Belenguer Cebrià (eds.), Calderón de la Barca y la España del Barroco (pp. 15-39). Madrid: Centro de Estudios Políticos y Constitucionales.

Mena García, C. (2004). Nuevos datos sobre bastimentos y envases en armadas y flotas de la Carrera, Revista de Indias, 64(231), 2004, pp. 447-484.

Newson, L.A. y Minchin, S. (2007). From capture to Sale: the Portuguese slave trade to Spanish South America Century. Leiden: BRILL.

Otero Lana, E. (2005). El corso del Flandes español como factor de guerra económica. Studia bistorica. Historia moderna, 27, 111-133.

Parker, G. (1985). The army of Flanders and the Spanish Road, 1567-1659. Cambridge: Cambridge University Press.

Pulido Serrano, J. I. (2002). Injurias a Cristo: religión, política y anti judaísmo en el siglo XVII. Madrid: Universidad de Alcalá de Henares.

Pulido Serrano, J. I. (2014). El Consejo de Portugal y las élites financieras portuguesas en la corte de la Monarquía Hispánica. Finanzas y tesoreros de la hermandad, hospital e iglesia de San Antonio de los Portugueses. En B. J. García García, y O. Recio Morales, O. (eds.), Las corporaciones de nación en la Monarquía Hispánica (1580-1750) (pp. 35-59).. Madrid: Fundación Carlos de Amberes.

Ruiz Martín, F. (1990). Las finanzas de la Monarquía Hispánica en tiempos de Felipe IV (1621-1665). Madrid: RAH.

Ediciones Universidad de Salamanca / @®@@ Stud. his., H. ${ }^{a}$ mod., 42, n. 2 (2020), pp. 255-288 
JAVIER GÓMEZ MESAS

LOS PEREIRA, CARDOSO Y LADRÓN DE GUEVARA: TRES FAMILIAS ESPECIALIZADAS

EN EL ABASTECIMIENTO DE PERTRECHOS Y BASTIMENTOS NAVALES EN EL REINADO DE FELIPE IV

Rodríguez Grajera, A. (2015). En J. J. Iglesias Rodríguez, R. M. Pérez García, M. F. Fernández Chaves (eds.), Comercio y cultura en la Edad Moderna. Actas de la XIII Reunión Cientifica de la FEHM (pp. 961-973). Sevilla: Editorial Universidad de Sevilla.

Sanz Ayán, C. (1989). Los banqueros de Carlos II. Valladolid: Universidad de Valladolid. Sanz Ayán, C. (1992). Negociadores y capitales en los sistemas de abastecimientos de pertrechos navales de la Monarquía Hispánica durante el siglo XVII. Hispania. Revista Española de Historia, 52(182), 915-945.

Sanz Ayán, C. (1998). Blasones son escudos: el ascenso económico y social de un asentista del rey en el siglo XVII, Bentura Donis. Cuadernos de Historia Moderna, 20, 33-57.

Sanz Ayán, C. (2004). Estado, monarquía y finanzas: estudios de Historia Financiera en tiempos de los Austrias. Madrid: Centro de Estudios Políticos y Constitucionales.

Sanz Ayán, C. (2013). Los banqueros y la crisis de la Monarquía Hispánica de 1640. Madrid: Marcial Pons.

Sanz Ayán, C. (2015). Un banquero en el Siglo de Oro. Madrid: La Esfera de los Libros.

Sánchez Durán, Á. (2018). Familia, parentesco y estrategias matrimoniales: hombres de negocios de la nación portuguesa en la Corona de Castilla (siglo XVII). En M. A. Pérez Samper y J. L. Betrán Moya (eds.), Nuevas perspectivas de investigación de Historia Moderna: economía, sociedad, politica y cultura en el mundo bispánico. Madrid: Fundación Española de Historia Moderna, 214-226.

Seiz Rodrigo, D. (2010). La disimulación honesta: los gastos secretos en el reinado de Felipe IV entre la razón de Estado y la merced cortesana. Madrid: Endymion.

Serrano Mangas, F. (1983). Los pertrechos extranjeros para los galeones de la Carrera de Indias en la segunda mitad del siglo XVII. Temas Americanistas, 2, 21-26.

Serrano Mangas, F. (1989). Armadas y flotas de la plata (1620-1648). Madrid: Banco de España.

Stradling, R.A. (1992). La Armada de Flandes. Política naval española y guerra europea (1568-1668). Madrid: Cátedra.

Stundicki-Gizbert, D. (2007). A nation upon the Ocean Sea. Portugal's Atlantic diaspora and the crisis of the Spanish Empire, 1492-1640. Oxford: Oxford University Press.

Taylor, H. (1972). Trade, Neutrality, and the «English Road», 1630-1648, Economic History Review, 2, 236-260.

Torres Ramírez, B. (1981). La Armada de Barlovento. Sevilla: Escuela de Estudios Hispano-Americanos.

Torres Sánchez, R. (2013). Administración o asiento: la política estatal de suministros militares en la monarquía española del siglo XVIII. Studia historica. Historia moderna, 35, 159-199.

\section{PÁGINAS WEB}

Sanz Ayán, C. Martín Ladrón de Guevara. Recuperado de: http://dbe.rah.es/biografias/90242/martin-ladron-de-guevara

Álvarez Nogal, C. Vicenzo Squarzafigo. Recuperado de: http://dbe.rah.es/biografias/75681/ vicencio-squarzafigo

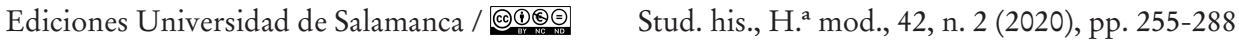

